University of Louisville

ThinkIR: The University of Louisville's Institutional Repository

8-2002

\title{
Unconventional therapies : individual factors associated with use, perceptions of function and efficacy.
}

Kenneth George Lombart 1954-

University of Louisville

Follow this and additional works at: https://ir.library.louisville.edu/etd

\section{Recommended Citation}

Lombart, Kenneth George 1954-, "Unconventional therapies : individual factors associated with use, perceptions of function and efficacy." (2002). Electronic Theses and Dissertations. Paper 851.

https://doi.org/10.18297/etd/851

This Doctoral Dissertation is brought to you for free and open access by ThinkIR: The University of Louisville's Institutional Repository. It has been accepted for inclusion in Electronic Theses and Dissertations by an authorized administrator of ThinkIR: The University of Louisville's Institutional Repository. This title appears here courtesy of the author, who has retained all other copyrights. For more information, please contact thinkir@louisville.edu. 
UNCONVENTIONAL THERAPIES: INDIVIDUAL FACTORS ASSOCIATED WITH USE, PERCEPTIONS OF FUNCTION AND EFFICACY

By

Kenneth George Lombart

B.S., United States Naval Academy, 1976

M.S.E.E., Naval Postgraduate School, 1984

M.A., University of New Haven, 1993

M.A., University of Louisville, 1998

\author{
A Dissertation \\ Submitted to the Faculty of the \\ Graduate School of the University of Louisville \\ in Partial Fulfillment of the Requirements \\ for the Degree of \\ Doctor of Philosophy \\ Department of Psychological and Brain Sciences \\ University of Louisville \\ Louisville, Kentucky
}

August 2002 
UNCONVENTIONAL THERAPIES: INDIVIDUAL FACTORS ASSOCIATED WITH USE, PERCEPTIONS OF FUNCTION AND EFFICACY

$$
\text { By }
$$

Kenneth George Lombart

B.S., United States Naval Academy, 1976

M.S.E.E., Naval Postgraduate School, 1984

M.A., University of New Haven, 1993

M.A., University of Louisville, 1998

\section{A Dissertation Approved on}

April 30, 2002

by the following Dissertation Committee:

Dissertation Director 


\section{DEDICATION}

This dissertation is dedicated to my mother

Laurel M. Lavell. 


\section{ACKNOWLEDGMENTS}

A dissertation is an endeavor of such magnitude and scope that it is not something done without the help of many other people. I take this opportunity to thank at least some of the individuals who provided invaluable assistance. First, the members of my dissertation committee. Paul G. Salmon, Ph.D., chairperson of the committee, has mentored me throughout my research career as a graduate student at the University of Louisville and helped me develop my research and professional writing skills. John C. Birkimer, Ph.D. provided timely and useful assistance in the choice of instruments and use of statistics for analyses. Stanley A. Murrell, Ph.D. provided a sounding board for the reasonableness of my ideas and approaches on many occasions. It also seemed that either Dr. Birkimer or Dr. Murrell was available anytime I was discouraged and needed to talk through a problem I was having with this study. Robert G. Meyer, Ph.D. was always clear about specific suggestions and helped me find and articulate the focus for this project. G. Randall Schrodt, M.D. shared his vast knowledge of and experiences with the field of complementary and alternative medicine.

My thanks also to those who helped in finding members of the general population to participate in this project. The Reverend John Hines, interim rector of St. Luke's Episcopal Church in Anchorage, KY, the Reverend Paul Jeans, rector of St. James' Episcopal Church in Pee Wee Valley, KY, Reverend Jim Miller, pastor of Lampton Baptist Church in Louisville, KY, and their respective church secretaries, Margaret, Susan, and Candace, assisted me in using their church facilities and recruiting their 
parishioners as participants. John Hines also helped me find other locations to recruit participants. Bob LaMontagne introduced me to several employees of Brown-Forman Corporation who agreed to participate. He also arranged a generous space at BrownForman for administering the survey instruments.

To the Introduction to Psychology Students at the University of Louisville and members of the Louisville community who participated and completed my surveys, my deep gratitude. Without each of you, this study would never have taken place.

Finally, my very special thanks to Edna L. Ross, Ph.D. It would be impossible to enumerate the many ways she assisted in recruiting Introduction to Psychology and general population participants and helped me maintain my focus and sense of humor throughout data collection and drafts of this paper. I hope that we may collaborate on future research. 


\section{ABSTRACT \\ Unconventional Therapies: Individual Factors Associated with Use, Perceptions of Function and Efficacy \\ Kenneth George Lombart}

August 9, 2002

There has been an increasing use of Unconventional Therapies in the past decade. These refer to healthcare interventions representing either a compliment or alternative to traditional medicine to which many people have turned in hope of attaining a fuller, more healthy life. Previous research has focused on overall use, or use of general types, of these therapies. Research has also started delving into mechanisms of change and physical and psychological effects of some specific therapies. The present study examined individual factors of personality, locus of control, health values, desirable responding, age, medical conditions, and transformational events to determine associations with use and perceived efficacy of 10 specific therapies. Three other areas were explored: participants' functional groupings of these therapies were compared to major domains used by the National Center for Complementary and Alternative Medicine; individual factors were examined for patterns associated with having tried each; and patterns were sought for associations with perceived efficacy of each.

Participants were 160 adults, ages 18 to 73 years. Of these, 102 were introductory psychology students from the University of Louisville and 58 were residents of the same metropolitan area. Therapies surveyed were Acupuncture, Chiropractic, Ginkgo biloba, Hypnosis, Magnet, Massage, Meditation, Ornish (reversal) diet, 
Therapeutic touch, and Yoga. Being older and higher in the personality factor Openness to new experience were associated with having tried more therapies, explaining $14.6 \%$ of the variance in number tried. Being younger and using less impression management were associated with greater perceived efficacy of therapies tried, but accounted for only $8.3 \%$ of the variance in perceived efficacy. Identification of primary therapeutic functions showed agreement rates from $30.2 \%$ (Therapeutic touch) to $83.4 \%$ (Meditation) with the National Center for Complementary and Alternative Medicine major domains for the therapies. Individual factor patterns for use and perceived efficacy were developed for the surveyed therapies, using discriminant function and regression analyses.

The individual factor patterns developed in this study provide a starting point for future research into the use and perceived effectiveness of specific unconventional therapies. Future research into perceived efficacy should recruit individuals who have tried the therapies of interest. 
TABLE OF CONTENTS

PAGE

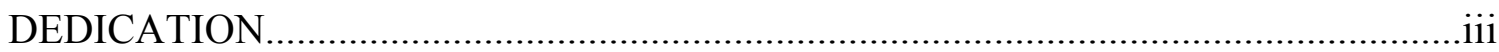

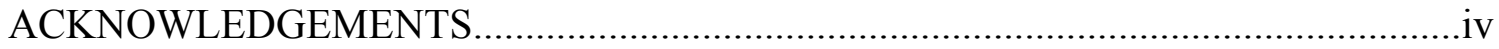

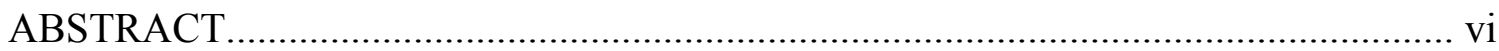

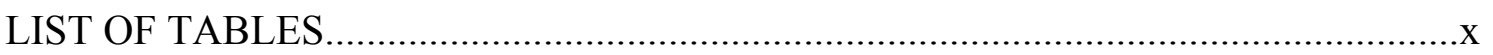

\section{CHAPTER}

I INTRODUCTION AND OVERVIEW .......................................................

Section 1: Unconventional Therapies....................................................

Section 2: Individual Difference Factors and Unconventional Therapies............13

Section 3: Perceived Functions and Efficacy of Unconventional Therapies........18

Section 4: Hypotheses and Exploratory Analyses.........................................24

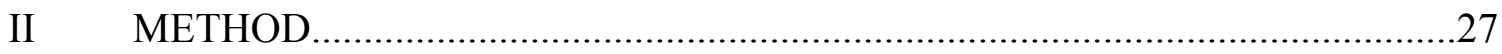

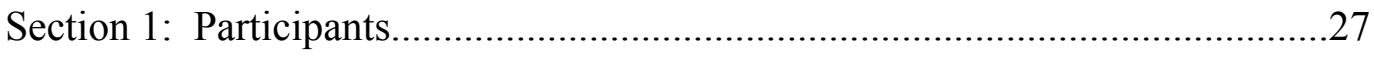

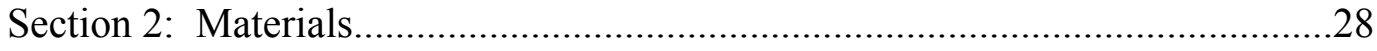

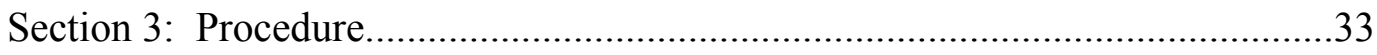

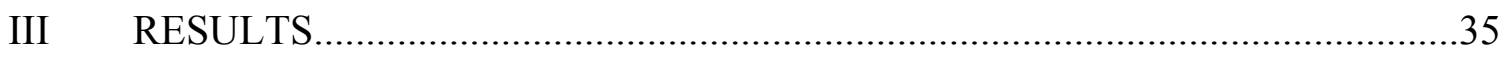

Section 1: Power Analysis and Effect Size...................................................35

Section 2: Sample Demographic Characteristics..............................................35

Section 3: Response Patterns for Study Questionnaires...................................37

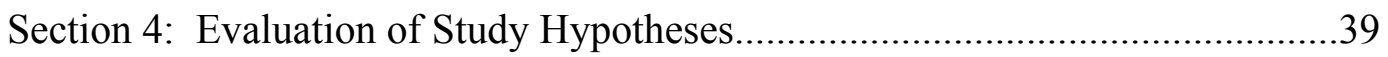


Section 5: Exploratory Analyses.......................................................................42

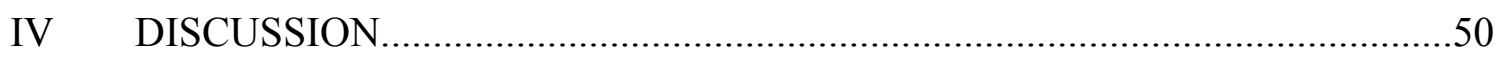

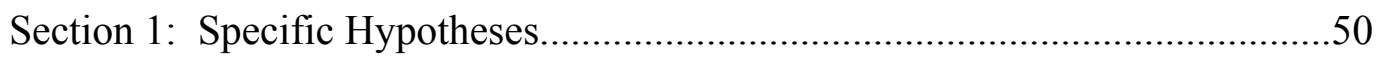

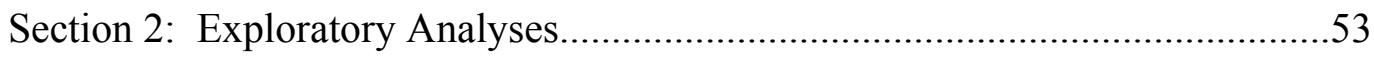

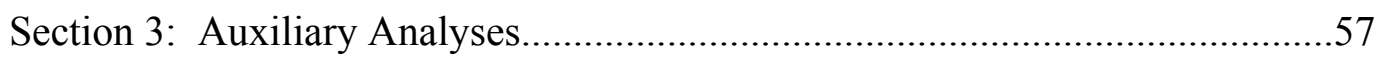

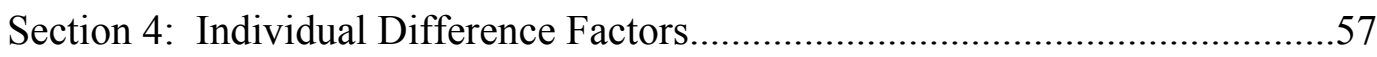

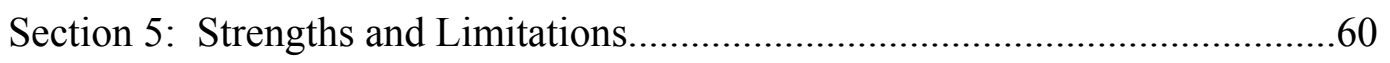

Section 6: Suggestions for Future Research.........................................................61

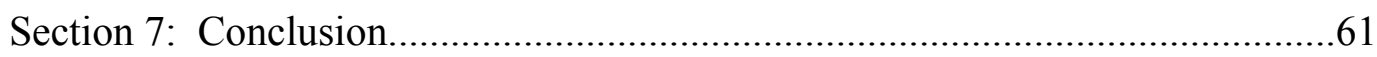

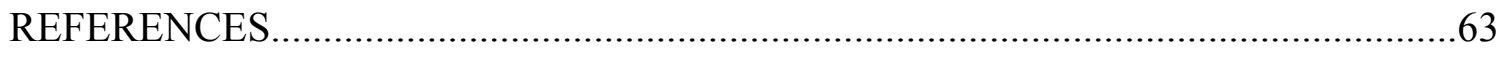

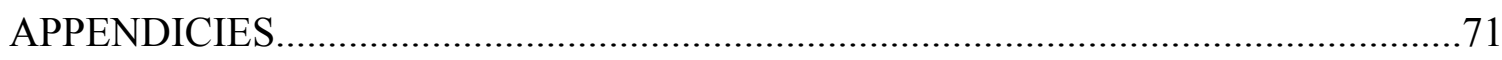

Appendix A: NEO-PI-R Factors and Facets: A Brief Description..........................71

Appendix B: Background Information Questionnaire..........................................76

Appendix C: Locus of Control...........................................................................77

Appendix D: The Extended Health Values Scale.................................................... 81

Appendix E: Balanced Inventory of Desirable Responding - 40..........................82

Appendix F: Perceptions of Unconventional Therapies Questionnaire..................85

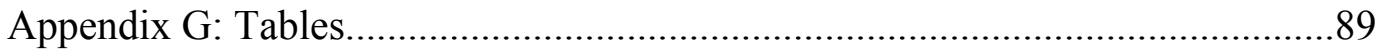

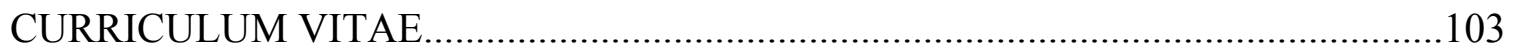




\section{LIST OF TABLES}

TABLE $\quad$ PAGE

1. Demographic Information of This and Past Studies.....................................89

2. Number of Primary Medical Conditions Reported in This and Previous Study .90

3. Transformational Events Experienced.....................................................91

4. Mean T-scores for Each NEO-PI-R Personality Factor...................................92

5. Analysis of Variance Comparison of NEO-PI-R Factor T-scores

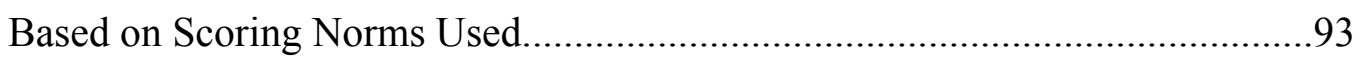

6. Participant Scores on Locus of Control, Extended Health Values Scale, and Balanced Inventory of Desirable Responding........................................99

7. Percent of Sample Having Heard of and Tried Each Surveyed

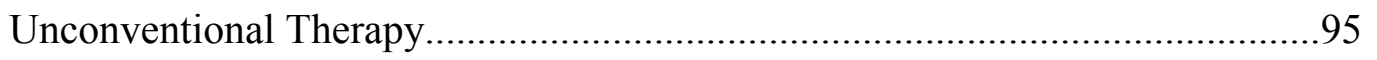

8. Conditions for Which Acupuncture, Chiropractic, and Ginkgo Biloba

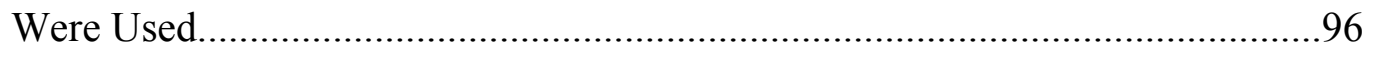

9. Conditions for Which Hypnosis, Magnet therapy, and Massage Were Used......97

10. Conditions for Which Meditation, Ornish Diet, Therapeutic Touch,

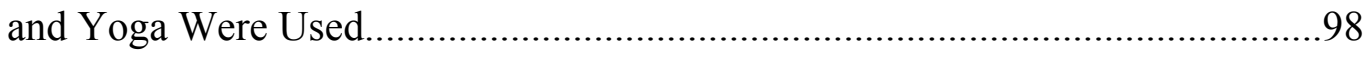

11. Regression and correlation Coefficients for Predictor Variables in

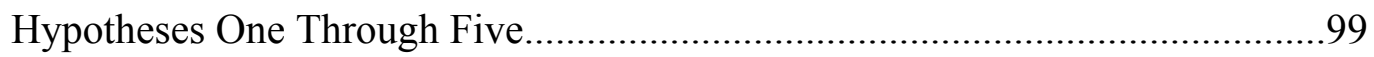


12. Regression and correlation Coefficients for Predictor Variables in

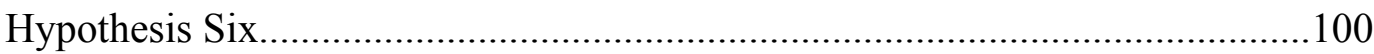

13. Overall Perceived Efficacy and Perceived Effectiveness of Individual

Unconventional Therapies

Tried................................................................. 101

14. Functional Perceptions of Unconventional Therapies Compared to

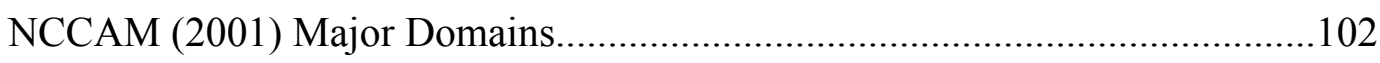




\section{CHAPTER I}

\section{INTRODUCTION AND OVERVIEW}

While president of the American Psychological Association (APA), Seligman encouraged psychologists to broaden our research horizons beyond traditional psychotherapy research into areas of interest to the broader population. This included discovering new ways to help improve people's lives, such as promoting health and wellness (Seligman, 1998a). He followed this with a call for systematic study of qualities that make life more worthwhile (Seligman, 1998b) and termed this "Positive Psychology" (Seligman, 1998c, p. 2). In his final President's Column of the APA Monitor, he emphasized the importance of psychology working to systematically investigate and foster attitudinal factors such as hope and optimism (Seligman, 1998d). In a related vein, one area of great interest in the broader U.S. population is what has been termed 'Unconventional Therapies,' or simply UT (British Medical Journal, 1996; Eisenberg et al., 1998; Eisenberg, Kessler, Foster, Norlock, Calkins, \& Delbanco, 1993; MacLennan, Wilson, \& Taylor, 1996; Paramore, 1997). 'Unconventional Therapies' refer to healthcare interventions representing either a complement or alternative to traditional medicine to which many people have turned in the hope of attaining a fuller, more healthy life. It might be said that whereas traditional medicine focuses on curing disease, UT promote a broader process of 'healing,' on that encompasses not only the patient's physical status, but psychological adaptation as well.

The Introduction and Overview chapter of this study is organized into the 
following four sections: 1) Review of the unconventional therapy literature; 2) individual difference factors and the unconventional therapies; 3 ) perceived functions and efficacy of unconventional therapies; and 4) the hypotheses and exploratory analyses of the current study.

\section{Section 1: Unconventional Therapy}

The term Unconventional Therapy is used to describe "medical interventions not taught widely at U.S. medical schools or generally available at U.S. hospitals" (Eisenberg et al., 1993, p. 246). These therapies generally meet the following criteria set forth by the National Center for Complementary and Alternative Medicine (NCCAM; formerly the Office of Alternative Medicine) of the National Institutes of Health: 1) Although widely practiced, neither their effectiveness nor safety have been unambiguously documented on the basis of systematic research; 2) they are not routinely taught or practiced in U.S. medical schools; and 3) health insurance providers do not generally provide financial reimbursement for their use (Stalker, 1995). Other terms have been used synonymously with UT in the literature, including Alternative, Complementary, Unconventional, and Unorthodox Medicine, as well as Alternative or Unorthodox Therapy. Irrespective of the terminology used, UT are clinical interventions with alleged health-restoring benefits but which do not presently meet current medical practice standards (Gevitz, 1988).

Examples of UT in widespread use include Chiropractic care; herbal remedies and supplements; massage; meditation; and yoga.

Systematic research on the effect of UT is currently in its infancy, and marked by three trends. First, early research centered on such basic issues as prevalence, cost, and patterns of use (Astin, 1998; Astin, Pelletier, Marie, \& Haskell, 2000; Eisenberg et al., 1993, 1998; Flaherty et al., 2001; Fisher \& Ward, 1994; Foster, Phillips, Hamel, \& 
Eisenberg, 2000; Millar, 1997; Paramore, 1997). Second, surveys of traditional health care providers (primarily physicians) have been conducted evaluating their attitudes toward UT and their incorporation into clinical practice (American Medical Association Council on Medical Education, 1997; Carlson, Stuart, \& Jonas, 1997; The Federation of State Medical Boards, 1997; Muehsam, 1997; Pelletier, Marie, Krasner, \& Haskell, 1997; Wetzel, Eisenberg, \& Kaptchuk, 1998). Finally, many UT have, or are currently undergoing, clinical trials to evaluate their effectiveness (Bernstein, 2000; Davidson \& Connor, 2001; Davidson et al., 2002; Engle \& Graney, 2000; Fornal, Metzler, Mirescu, Stein, \& Jacobs, 2001; Gilbar, Iron, \& Goren, 2001; Ito, Trant, \& Polan, 2001; Karst, Rollnik, Fink, Reinhard, \& Prepenbrock, 2000; Lu, Lu, \& Kleinman, 2001; Pyevich \& Bogenshutz, 2001; Richard, Kowaldo, \& Gibbs, 2001; Roeschke et al., 2000; Umezu, Sakata, \& Ito, 2001; Yobimoto et al., 2000). Research in each of these three areas will now be reviewed.

\section{Prevalence and Cost of Unconventional Therapies}

Popular interest in UT is apparent from several survey studies over the last decade designed to assess their prevalence in the context of healthcare. For example, Eisenberg and colleagues (1993) conducted a telephone survey of 1539 individuals, exploring the prevalence, cost, and patterns of use of UT in 1990. The UT included in this study were Acupuncture, Biofeedback, Chiropractic, Commercial weight-loss programs, Energy healing, Folk remedies, Herbal medicine, Homeopathy, Hypnosis, Imagery, Lifestyle diets, Megavitamin therapy, Massage, Relaxation techniques, Self-help groups, and Spiritual healing. This survey also requested information on the use of exercise and prayer. Demographic characteristics of this sample are shown in Table 1.

This study found that $34 \%$ of participants had used one or more UT, excluding 
exercise and prayer, in the previous year. In addition, $36 \%$ of those using such therapies had visited a provider of UT in that 12 month period with an average of 19 visits. National projections from this study suggested that 61 million people in the U.S. had used at least one of these UT in the previous year, with 22 million seeing a provider of UT for their primary medical condition(s). The projected cost of these interventions was $\$ 13.7$ billion, with $\$ 10.3$ billion paid out-of-pocket. These figures represent about half of the out-of-pocket payments in the U.S. for all medical services (\$23.5 billion) in 1990. The authors noted that this was likely an underestimate of the use and cost of UT, since they found greater use of UT by those in poorer health and their study participants represented an under reporting of poorer health compared to the national average (Eisenberg et al., 1993).

Using a large sample (3450 respondents) from the Robert Wood Johnson Foundation National Access to Care Survey, Paramore (1997) examined the prevalence of use of several UT. These included Chiropractic, Relaxation techniques, Therapeutic massage, and Acupuncture. Population projections indicated that 25 million people, nearly $10 \%$ of the U.S. population, visited a provider of one or more of these four therapies in 1994 (Paramore, 1997).

As a follow-up to the Eisenberg et al. (1993) study, Eisenberg and associates (1998) again looked at the use of the same set of UT in 1997 and compared them to the figures for 1990. In a telephone survey, 2055 participants described their use of UT over the previous year. Results showed that use of one or more of these therapies had increased to $42 \%$, with $46 \%$ of users visiting a practitioner of UT an average of 16 times in that 12 month period. National projections from this study indicated that 83 million people made 629 million visits to practitioners of UT, representing 243 million more 
visits than were made to primary care physicians in the U.S. during the same period. The projected out-of-pocket costs of UT also rose to between $\$ 27.0$ and $\$ 34.4$ billion, compared to $\$ 29.3$ billion for all physician services in the U.S. during the same period (Eisenberg et al., 1998). The data from these studies show an increasing trend in the use and out-of-pocket costs of UT in the U.S. over the last decade.

Use of therapies that are unconventional to western medicine is not limited to the U.S. Using 17,626 respondents to the 1994-1995 Canadian National Population Health Survey, Millar (1997) projected that 15\% of the Canadian population had visited a provider of UT in the year preceding the study. The therapy providers included in this research included: Acupuncturist, Biofeedback teacher, Feldenrais or Alexander teacher, Herbalist, Homeopath or naturopath, Massage therapist, Reflexologist, Relaxation therapist, Religious leader, Rolfer, Self-help group, and Spiritual healer.

Europe has also seen an increasing trend in the use of UT. Although the regulation, practice, and reimbursement of UT varies from country to country in Western Europe, each showed increases from the early 1980's to the early 1990's with prevalence ranging from 23\% in Denmark to 49\% in France. These figures include UT obtained from conventional physicians, and were not necessarily consistent in which therapies were considered unconventional from country to country (Fisher \& Ward, 1994).

A survey of sampled countries worldwide, in the early to middle 1990's, indicated prevalence rates of UT from 10\% in Britain to 33\% in Australia to 50\% in Russia and $60 \%$ in Japan. The high rate of use in Japan was attributed to wide use of traditional Japanese medicine, which is not part of Japanese medical degree programs (British Medical Journal, 1996).

Although the aforementioned studies differ in specifics, including which specific 
UT were included, they all indicate significant popular interest in treatments that historically have not been generally recognized and sanctioned by the medical community. The studies by Eisenberg and colleagues $(1993,1998)$ point to an increasing trend in this interest in the U.S. This is supported not only by the numbers who are using these therapies and the numbers of visits to practitioners, but more poignantly by the monetary investment those in the U.S. are making to receive these therapies.

\section{Professional Attention to Unconventional Therapies}

This trend has not gone unnoticed by various segments of the American health care system. In a recent survey of health insurance companies, hospital providers, and managed care companies, Pelletier and colleagues (1997) found that many of these companies had started covering some forms of UT. These generally included Acupuncture, Biofeedback, Chiropractic, Nutrition counseling, Osteopathy, Physical therapy, Preventive medicine, and Psychotherapy. The general consensus among carriers appeared to be that additional information was needed about the cost-benefit and efficacy of, and consumer interest in, the specific therapies for them to expand coverage to other forms. Of the 18 insurers sampled, $67 \%$ (12) indicated that a primary reason for covering specific UT was the market demand of their consumers (Pelletier, 1997).

Some medical schools in the U.S. have recognized the trend toward popular use of UT as well. In a sample of 117 U.S. medical schools, $64 \%$ reported attention to these therapies. This attention varied from including aspects of these therapies in required courses $(31 \%)$, to stand-alone electives dealing with these therapies $(68 \%)$, to being part of an elective course (1\%). The most common topics included in these formats included Acupuncture, Chiropractic, Herbal therapies, Homeopathy, and Mind-body techniques (Wetzel et al., 1998). 
Several other organizations have also focused attention on UT as recently as 1997. These include special interest groups formed by the American Public Health Association, the Group on Educational Affairs of the Association of American Medical Colleges, and the Society of Teachers of Family Medicine (American Medical Association Council on Medical Education, 1997; Carlson et al., 1997; Muehsam, 1997). In addition, development of educational opportunities for legislators, licensees, and consumers has been recommended by The Federation of State Medical Boards (1997).

\section{Clinical Research}

Researchers have started examining the effects of various UT as treatments and as adjuncts to conventional treatments. Basic animal research has investigated the effect of natural substances on various functions. This has included examining the antidepressant (seretonergic) effects of St. John's wort on neural activity in cats (Fornal et al., 2001), the memory enhancement effects of Ginkgo biloba on chicken memory formation (Richard et al., 2001), the protective effects of ginseng against stress-related brain cell membrane damage in the brains of mice (Yobimoto et al., 2000), and the activity-inducing effects of peppermint oil on the ambulation of mice (Umezu et al., 2001).

Human research has been conducted as well. Case studies have included the effect of St. John's wort (Davidson \& Connor, 2001) and saliva divinorum (Hanes, 2001) on depression and herbal diuretics on lithium levels (Pyevich \& Bogenshutz, 2001). Controlled trials have also been reported on the effects of St. John's wort on Major Depressive Disorder (Davidson et al., 2002), acupuncture and hypnosis for pain (Lu et al., 2001), nutritional supplements on sexual function (Ito et al., 2001), acupuncture for headaches (Karst et al., 2000), and therapeutic touch on physiological responses (Engle \& Graney, 2000). With respect to adjunct treatments, Gilbar and associates (2001) 
investigated the addition of UT to conventional cancer treatment and their effect on psychological distress. The addition of acupuncture to conventional substance abuse treatment was examined for its effect on physical and psychological responses during withdrawal and treatment (Bernstein, 2000). The effect of acupuncture has also been reported as an adjunct to antidepressant medication (Roeschke et al., 2000).

Some treatment protocols that have been shown effective also include UT elements. Caudill (2002) has recently broadened the use of UT techniques in her pain management system to include an appendix of these techniques in addition to her use of the Relaxation Response (Benson, 1975) and elements of mindfulness. Linehan (1993) included mindfulness techniques and imagery in her protocol for the treatment of Borderline Personality Disorder.

Patterns of Use of Unconventional Therapies 
The increasing attention that UT are receiving has been well documented. This, however, raises the question of why so many people have been utilizing UT. Eisenberg and colleagues $(1993,1998)$ examined patterns of use, focusing on their list of 16 UT as a group and as individual therapies. Results indicated that $83 \%$ of those surveyed reported that they had one or more principle medical condition. Of these, $58 \%$ saw a physician but no UT provider; 7\% saw both a physician and a provider of UT; 3\% saw only an UT provider and no physician; and 33\% saw neither for their primary medical conditions. Demographically, UT use was more common 1) in the western U.S. than other areas, 2) among those with higher annual incomes (above $\$ 35,000$ ), 3) with those who had some college education, and 4) in those 25 to 49 years old compared to younger adults. Use of UT was less common among Blacks than other racial groups. No difference was found based on sex or insurance status. Use of UT occurred most frequently when primary health-related problems were anxiety, back problems, depression, headaches, or insomnia. One-half to one-third of those who saw a physician also saw a UT provider for the primary medical conditions of anxiety, obesity, back problems, depression, or chronic pain. Primary medical conditions for which individuals were least likely ( $12 \%$ or fewer) to utilize UT included pulmonary, dental, gynecologic, urinary, and dermatological problems, as well as diabetes and high blood pressure. Of those who saw a provider of UT, $89 \%$ did so without the recommendation of a physician and $72 \%$ did not inform their physicians of their use of UT. In addition, almost half (47\%) of those who reported using UT for a primary medical condition did so without consulting either a physician or a provider of UT, meaning they received no professional supervision (medical or non-medical) for their primary medical condition (Eisenberg et al., 1993, 1998). 
Since these initial prevalence studies, several researchers have also examined the use of UT specifically among population subgroups, including the elderly. Rates of use varied from about 30\% among 311 individuals contacted by telephone survey (Foster et al., 2000) to $41 \%$ among 728 by mailed survey (Astin et al., 2000) for those who were 65 years or older to over $50 \%$ among 593 respondents between the ages of 59 and 69 years who were surveyed at an outpatient medical clinic (Flaherty et al., 2001). Similar to the findings for the general population, these studies have all reported that fewer than half of those using one or more form of UT discussed or even mentioned this to their physicians.

Astin (1998) conducted a survey study that focused on reasons why people use UT, in an attempt to develop models to explain their use. The study explored several possible reasons for UT use, including: a) dissatisfaction with traditional medical care; b) need for personal control; and/or c) philosophical congruence with the prevailing medical treatment model. The concept of 'dissatisfaction' was further subdivided into questions dealing with the effectiveness, adverse effects, interpersonal qualities, and cost of conventional medical care. This study also investigated the effects of demographic and health status variables on the use of UT. Results showed the following seven factors to be predictive of UT use: 1) higher education level; 2) poorer health status; 3) health problems including anxiety, back problems, chronic pain, and urinary tract problems; 4) 'transformational experiences,' i.e., the occurrence of events which altered the person's world view; 5) an interest in spirituality and personal growth psychology; 6) a commitment to feminism; and 7) membership in a cultural group committed to environmentalism. In terms of the three principal areas of investigation (dissatisfaction, need for personal control, and philosophical congruence), the following patterns emerged. Concerning dissatisfaction, only a small percentage of those surveyed (4.4\%) 
relied primarily on UT, and dissatisfaction with conventional medicine was not predictive of UT use. In fact, $39 \%$ of those who were highly satisfied and $40 \%$ of those who were highly dissatisfied with their conventional practitioners were using UT. Second, 'need for personal control' did not emerge as a predictor of UT use in this study. However, it should be noted that Astin examined this construct using a single item referring specifically to control over medical conditions, not an overall evaluation of control needs related to the broader use of both traditional and unconventional therapies. Finally, an examination of the philosophical congruence factor suggested that this was an important factor. It was not clear from the description of these measures how Astin measured the predictiveness of transformational experiences and commitment to feminism, two factors which appeared to be related to the issue of philosophical congruence.

A question of some interest concerns the extent to which knowledge of, and interest in use of UT varies with population demographics. For example, is interest in UT confined solely to older adults, who are more likely to use them? There is in fact some evidence that younger individuals, specifically college students, have both knowledge and opinions about UT. An unpublished study of 207 undergraduate students in an Introduction to Psychology course at a large Midwestern University (Lombart, 1998) examined preferences for stress management practices based on either traditional (Stress Inoculation Training, Meichenbaum, 1993) or UT-related (Mindfulness Meditation, Kabat-Zinn, 1982) intervention modes. Participants read unlabeled descriptions of each of the two specific treatments and rated their preferences. More than half (60.9\%) indicated a preference for Mindfulness Meditation, suggesting at least some openness to UT. Results of this study are consistent with another investigation of this same population by Scott (1999), who reported that willingness to use UT was positively 
associated with both knowledge of and experience with such therapies. Taken together, previous studies and surveys of patients and introductory psychology students in this metropolitan area indicated that it would be appropriate to include members of both groups in a study concerning the use and perceptions of UT in this geographic area.

To summarize, there is a fairly extensive body of survey research concerning familiarity with and use of UT. Previous studies have investigated a range of variables related to their use, including demographics (sex, race, income, and education) and medical diagnoses of survey participants. Results of these studies may be summarized as follows. First, nearly half the U.S. population is using one or more UT each year and that proportion in increasing. Second, annual out-of-pocket expenses for these therapies are on a par with physician related expenses. Third, the use of UT is more common in the Western U.S., among those with higher income and more education, and among those with poorer health. It is also more commonly used among those with: 1) an interest in personal growth psychology; 2) a commitment to feminism; and 3) membership in a cultural group committed to environmentalism. Fourth, there is not a significant difference in the use of these therapies based on sex, insurance status, or level of satisfaction with traditional health care. Fifth, Blacks are less likely to use them than other racial groups. Sixth, UT are more likely to be used for anxiety, back problems, chronic pain, depression, and obesity, and less likely to be used for high blood pressure, and problems with lungs, reproduction, skin, and teeth.

On balance, research to date concerning the use of UT has not addressed several key issues. First, there have been no systematic investigations of the extent to which personality or related individual difference factors may contribute to either knowledge of or use of UT. Second, relatively little is known about perceptions of UT and their 
purported function. Finally, research is needed to assess the impact of UT, in terms of their perceived effectiveness.

\section{Section 2: Individual Difference Factors and Unconventional Therapies}

The purpose of this study was to investigate a group of four factors which, on the basis of both previous research findings and limitations, needed to be assessed more fully in order to obtain a clearer understanding of reasons for the widespread use of UT. These factors are: 1) Personality variables; 2) Locus of Control; 3) health values; and 4) unique personal experiences (so-called 'transformational life events') that might influence the choice and nature of health care interventions. Each of these will now be described.

With respect to personality factors, previous research has shown that people who have used UT represent a broad range of the population (Astin, 1998; Eisenberg et al., 1993, 1998), and any assessment of personality factors should therefore be based on normative, rather than clinical, assessment measures. Moreover, personality factors have been strongly linked to health and health related behaviors (Sarafino, 1994), further justifying the use of a non-clinical measure. The instrument selected for this study was the NEO-PI-R (Costa \& McCrae, 1992), among the most widely used personality inventories in use.

NEO-PI-R 
The NEO-PI-R is the most recent embodiment of the long line of psychometric personality measures dating back to the work of Allport (John, 1990). A five-factor model of personality was developed by Tupes and Christal using factor analysis. Goldberg labeled these the "Big Five" to illustrate that each factor summarizes many distinct personality characteristics and that each factor is therefore very broad. This model has been replicated to confirm its factor structure (John, 1990). The personality traits represented by these five factors provide a measure for examining individual differences that may predispose people to make unique choices.

Costa and McCrae (1985) developed an inventory intended to specifically operationalize these five personality factors, the NEO-PI. This instrument has a hierarchical structure providing a concise measure of five broad domains ("the Big Five") as well as six facets within each domain, providing a comprehensive assessment of personality. Unlike most personality inventories, the NEO-PI-R was developed to measure the broad range of personality attributes, not just negative affect and interpersonal activity relevant to clinical applications (McCrae \& John, 1992). In addition, the NEO-PI-R has been useful in research about health and health-related attitudes and behaviors. This line of research has included examining links between personality factors and: 1) Perceived well-being (Costa, McCrae, \& Zonderman, 1987; Siegler \& Brummett, 2000); 2) chest pain (Costa, 1987); 3) coping with health issues (Bosworth, Feaganes, Vitaliano, Mark, \& Siegler, 2001); and 4) healthy behaviors, such as smoking cessation (Baile et al., 1984) and getting regular mammograms (Siegler, Feaganes, \& Rimer, 1995). The NEO-PI-R has also been used to help clarify the link between hostility and heart disease (Costa, Krantz, Blumenthal, \& Furberg, 1987; Dembroski \& Costa, 1987). 
The five personality factors are labeled Neuroticism, Extraversion, Openness to Experience (openness), Agreeableness, and Conscientiousness. The individual characteristics of these factors and each of their facets are described briefly in Appendix A. The following section describes possible associations between NEO-PI-R factor and facet characteristics and the use and perceived effectiveness of UT.

Neuroticism. The UT are different from the medical interventions to which most people have been exposed as part of their up bringing. The fear and guilt of neuroticism, particularly the apprehensiveness and fearfulness of the anxiety facet and the interpersonal discomfort of the self-consciousness facet suggest those lower in Neuroticism may be more likely to try these less known treatments than those who are higher in this domain.

Extraversion. The friendliness and excitement seeking associated with higher levels of Extraversion suggest those higher in this trait may have more of a tendency toward trying UT because of their difference from conventional medicine. This would particularly relevant for the combination of gregariousness, assertiveness, and excitement seeking.

Openness. Since the UT are likely to be new experiences for most of the population, the characteristics associated with higher levels of openness and each of its facets suggest a greater likelihood of trying the UT.

Agreeableness. Higher levels of agreeableness suggest trust and satisfaction with the way things are and lower levels of this trait suggest a distrust or disdain for new things as well as things which are known. This would appear likely for several of the facets as well. Those high in trust would likely be satisfied that they are getting proper care from conventional medicine and be satisfied with their health care. This satisfaction 
would not suggest exploration of other forms of therapy. Those low in this facet are probably equally unlikely to trust new approaches, as they are to do with the conventional ones. Those high in compliance would appear unlikely to veer from the treatment regimens of conventional therapies. While those low in this facet may be more likely to try UT, it is unlikely that they would comply with any UT any more than they would a conventional therapy. This suggests that if those low in compliance have tried UT, they will not perceive them to have been effective. The humility associated with high levels of the modesty facet would suggest such individuals would be unlikely to try a UT unless recommended by a conventional practitioner. Those particularly low in this facet may be more likely to try a UT that does not involve a practitioner.

Conscientiousness. Only the dutifulness facet of conscientiousness suggests an association with trying UT. Those scoring high in this facet would appear less likely to try these therapies. However, the qualities associated with this facet suggest that if those high in dutifulness did try a UT, they would probably get as much out of it as they could and perceive it as having been helpful.

Another aspect of individual factors is the perception one has of the control of his or her life. Astin (1998) found that high Internal Health Locus of Control (HLOC; Walston, 1976) predicted use of UT. Although HLOC is a useful construct in examining health related behaviors, the present study has taken the broader perspective of looking at the interaction of individual factors with overall style of coping. One particular aspect of personality, which has been associated with style of coping, is Locus of Control.

Locus of Control 
The second individual difference variable assessed in this study is Locus of Control (LOC), a measure of the degree to which people are internally or externally oriented with respect to perceived control in their lives. Levenson (1973a) modified the Internal-External (I-E) LOC scale (Rotter, 1966) for assessment, to provide an accurate measure of control expectancy with respect to psychological interventions. This scale measures LOC on three dimensions. These are 'Internal,' 'Powerful Others,' and 'Chance.' Internal LOC is a measure of the extent to which an individual thinks the world is ordered and she or he is in control of the circumstances surrounding her or his life. Powerful others LOC is a measure of the extent to which the individual views the world as ordered, but with her or his circumstances as being controlled by other beings with power. Chance LOC measures the extent to which an individual views the circumstances in her or his life as being random occurrences that are not ordered (Levenson, 1973a, 1973b).

The characteristics associated with each locus of this scale suggest different likelihoods of trying UT. Those higher in internal control may be more likely to try these different techniques, possibly as a way of exercising their perceived control over their lives. Those higher in powerful others control may be less likely to try UT as their perception of the control of powerful others would include practitioners of conventional therapies. However, if those higher in powerful others control view the practice of UT as a form of 'powerful other,' they may be drawn to them. Consistent with their perception of the randomness of their lives, those high in chance control may try different treatments for their difficulties in the hope of finding one that happens to work for them; or they may 'not bother' trying anything different as improvement could be viewed as beyond their or anyone else's control. 
Related individual factors, which might be associated with the choice to use UT, are the view one holds about health and having experienced a transformational event in one's life.

\section{Health Values}

Lau, Hartman, and Ware (1986) developed a four-item health values scale. This was designed to determine the relative value one places on personal health. Although this scale showed moderate reliability (alpha $=.63$ to .72 ) and test-retest reliability (.62) for several diverse samples, it also had strong correlation with subscales of the HLOC scale. Buckley, Birkimer, and Beacham (2001) expanded the Lau and colleagues scale in an effort to increase reliability. The value one places on one's health. As measured by the Extended Health Values Scale (EHVS), may be associated with the use of UT as a means of achieving that value.

\section{Transformational Event}

The experience of major changes or major disruptions in life has been termed a 'Transformational Event' (Astin, 1998). The prevalence Astin found of these events among those who had used UT suggests a particularly compelling experience, or set of experiences, might predict the use of these therapies.

Individual difference factors and transformational events may help explain choosing to use an individual UT, or UT in general. But, similar to the way in which conventional medical interventions are not all used for the same purpose, it seems unlikely that individual UT would all be used for the same purpose.

Section 3: Perceived Functions and Efficacy of Unconventional Therapies 
On the surface, there would seem to be good reasons for examining the same UT surveyed by previous researchers (e.g., Astin, 1998; Eisenberg et al., 1993, 1998), as a way of extending and clarifying the small body of extant research to date. However, there is a more compelling reason not to do so. Some of the therapies surveyed in previous studies were individual therapies, such as Chiropractic, Massage, Imagery, and Spiritual healing. But, several represented groups of therapies. Examples include: 1) Lifestyle diets, such as Atkins and Ornish diets; 2) Energy healing, which includes Magnet therapy and Therapeutic touch, among others; and Herbal therapies, which encompass many specific therapies, such as Ginkgo biloba, St. John's wort, and Peppermint oil. The first of these groups readily exemplifies the difficulty of looking at the influence of individual difference factors on the use of a broad category. Lifestyle diets all involve changes in eating and related behavior patterns. They involve modifying the way food is used, meals are eaten, and related behaviors. However, there are marked differences among individual Lifestyle diets. For example, the Atkins diet advocates consumption of high protein and low carbohydrate foods (Block, 1999). In contrast, the Ornish (or reversal) diet recommends meals that are high in carbohydrates, moderately low in protein, and very low in fat (Block, 1999). Given these different approaches, it would not be surprising to find that individual difference factors determine the use of one versus the other. If studied as a single entity, individual variations associated with the personalized use of each might be lost.

This study focused on 10 specific UT in an attempt to discover individual variations associated with the use and perceived efficacy of each: Acupuncture; Chiropractic care; Ginkgo biloba; Hypnosis; Magnet therapy; Massage; Meditation; Ornish ('reversal') diet; Therapeutic touch; and Yoga. These 10 were selected to 
represent each of the major domains of UT used by NCCAM (2001). These domains are presented in the following sub-section.

Perceived Functions

NCCAM (2001) has classified the individual UT into five categories or major domains:

I Alternative Medical Systems

II Mind-Body Interventions

III Biological-Based Therapies

IV Manipulative and Body-Based Systems

V Energy Therapies

The therapies examined in this study, corresponding to each of these major domains, are as follows: I) Acupuncture, Massage, Meditation, and Yoga; II) Hypnosis, Meditation, and Yoga; III) Ginkgo biloba and Ornish diet; IV) Chiropractic and Massage; and V) Magnet therapy and Therapeutic touch. Although this is the classification system used by the NCCAM to characterize these therapies, the terminology does not necessarily reflect what those who use them hope to gain or achieve by their use. This study included an analysis of how people who have heard of these therapies describe their function and how well this perception fits with the NCCAM (2001) major domains for them.

The 10 UT of this study may be described as follows. As previously noted, neither effectiveness nor safety have been unambiguously documented on the basis of systematic research for the UT.

Acupuncture. Acupuncture is the process of inserting needles into one part of the body. Proponents use Acupuncture to relieve distress in an organ or another body part. 
Developed by meditative Chinese monks, this is a UT in the U.S. However, it has been a mainstay of traditional Chinese medicine for thousands of years (Choi \& Tweed, 1996; Gordon, 1996; Ernst, Rand, \& Stevenson, 1998).

Chiropractic. The chiropractor performs spinal and extremity manipulations to realign the skeletal system. Proponents of Chiropractic explain that this removes stress points in the body, thereby reducing pain and other symptoms such as nasal congestion (Gordon, 1996; Skargren \& Oeberg, 1998; Weil, 1995).

Ginkgo biloba. This derivative of the gingko leaf reduces platelet aggregation and appears to have antioxidant properties. Proponents have used it as an herbal supplement, claiming it improves memory, concentration, cerebral insufficiency, and asthma (Dog, 1999).

Hypnosis. Proponents of Hypnosis explain that it induces deep physical relaxation and mind calming. As a therapeutic technique, suggestions are made during a period of relaxation for later responses. Since critical and analytical thinking are reduced, individuals are thought to more easily employ fantasy and imagination for working through life problems. It is also hypothesized that they can mentally practice being calm and attentive and mentally rehearse actions. The deep relaxation experienced during hypnosis can also have benefits of calmness for longer periods after hypnosis (Barber, 1993).

Magnet therapy. This is a form of energy therapy. The use of magnets is presumed to alter the electromagnetic field around an area of the body. Proponents have used this to alleviate pain associated with arthritis (Gordon, 1996).

Massage. Massage includes any of over one hundred massage techniques that involve the stimulation of musculo-skeletal areas for relief. Relief may be in the form of 
reduction of muscle tension, stiffness, or pain (Cheung, 1999; Eisenberg et al., 1993; Gordon, 1996).

Meditation. During meditation, awareness is focused to allow a steadying and deepening of that awareness. Attention is directed to an external object, a thought or word, a physical sensation, or the attention itself. This is done to bring the mind and body into greater congruity. Various forms of meditation have been used successfully for reduction of stress and coping with chronic conditions (Baime, 1999; Kabat-Zinn, 1982).

Ornish or reversal diet. This is a diet which represents changes in the approach taken to both eating and general living. It involves modifications in the way food is used, meals are eaten, and the person lives his or her life. It was developed by Ornish (1990) to reverse heart disease. In its comprehensiveness, it includes a completely vegetarian diet, with reduced fat and sugar (natural as well as added) intake and increased fiber and complex carbohydrates in the form of fresh vegetables and whole grain foods. Eating is approached as a purposeful activity to reduce hunger. During meals, the individual attends to the food being eaten and minimizes outside distractions such as conversations, television, radio, reading, and thoughts about anything except the food being eaten. Other lifestyle changes in this program include regular exercise and stopping smoking.

Therapeutic touch. In this energy therapy form of spiritual healing, the practitioner either lightly touches or holds hands close to the body of the patient while focusing all thought on helping and healing the person. Proponents explain that this corrects unbalanced energy fields around the body and leads to relief of symptoms (Benor, 1999).

Yoga. Proponents use the breath control, attentional focus, and gentle stretching of Yoga to tone muscles, stimulate circulation, and improve overall health. It has been 
used for general self-improvement, stress reduction, and body toning (Jonas \& Levin, 1999).

Various individual differences undoubtedly contribute to the fact that some people chose to pursue and pay for UT, whereas others stick with 'tried and true' medical regimens. This choice is made despite the multitude of conventional therapies available, which are generally covered by insurance reimbursement, and which have been subjected to extensive scientific research and validation. In addition, discovering what individuals perceive as the main functions of these may help in understanding their patterns of use. However, a significant question still remains: Among those who have employed UT, what is their perception of the effectiveness of these strategies in accomplishing what they wanted when they used them?

To summarize, this chapter has provided an overview of research on current patterns of UT use. A variety of surveys have been conducted to help clarify reasons for widespread use of medically related interventions that constitute a sizeable economic investment. On the basis of this literature, the following conclusions appear warranted: 1) Nearly half the U.S. population is using one or more UT each year and annual out-ofpocket expenses for these therapies are on a par with physician related expenses; 2) UT use may be predicted by higher income, more education, poorer health, an interest in personal growth psychology, a commitment to feminism, and membership in a cultural group committed to environmentalism; 3 ) there is not a significant difference in the use of these therapies based on sex, insurance status, or level of satisfaction with traditional health care; and 4) Blacks are less likely to use them than other racial groups. The primary limitations of these studies may be summarized as follows: First, individual difference factors associated with use have not included personality variables, 
perceptions of control beyond medical decisions, or the value people place on health; second, they have not examined what people think the therapies do; third, satisfaction associated with the use of these therapies has not been determined; and finally, the therapies surveyed have often been groups or classes of therapies, not individual procedures. Based on these conclusions, the present study was undertaken to provide further clarification on the use of UT in a representative sampling of community members in a large metropolitan area.

\section{$\underline{\text { Section 4: Hypotheses and Exploratory Analyses }}$}

Eight hypotheses were tested and three exploratory analyses were performed in this study.

\section{Hypotheses}

This study hypothesized relationships between individual factors and the overall use and perceived effectiveness of the group of 10 UT surveyed. First, it predicted the relationship between specific personality variables and LOC with the number of UT that participants reported having tried (Hypotheses One through Five). Second, it reexamined the same relationship based on whether or not participants had experienced a transformational event in their lives (Hypothesis Six). Third, it examined whether introductory psychology students were more apt to have tried one or more UT than others were (Hypothesis Seven). Fourth, it examined the relationship between specific personality variables and the overall perceived efficacy of the UT tried (Hypothesis Eight). 


\section{Exploratory Analyses}

In addition to testing these hypothesized relationships, a series of exploratory analyses was performed with respect to the individual UT surveyed. There was not sufficient basis for forming formal hypotheses about these explorations. Therefore, the exploratory analyses are not tied to any specific hypotheses. First, the study explored the perceived major purpose of each UT. These were then compared to the NCCAM (2001) major domain(s) for each. Second, it sought to determine individual factors associated with the use of each surveyed UT. Third, it explored individual factors associated with greater perceived efficacy for each UT surveyed. The last two of these exploratory analyses were performed in an attempt to start building a bridge between medical professionals, who are showing interest in and receiving training in UT, and the public, who have an interest in and are using UT. Medical professionals who have the most frequent interactions with the public (e.g., Primary Care Physicians, Physicians' Assistants, and Nurse Practitioners) have very limited time to discuss not only UT, but also the myriad of conventional treatments available. These two explorations were designed to provide these professionals with indications of which patients might be open to, and which might perceive benefit from, the individual UT surveyed so they can use their limited time most beneficially for the patients.

\section{Specific Hypotheses}

The specific hypotheses of this study were:

Hypothesis One. Lower scores on the Neuroticism scale of the NEO-PI-R will be associated with use of more unconventional therapies.

Hypothesis Two. Those with higher scores on the Extraversion factor of the NEO-PI-R will be likely to have tried more unconventional therapies. 
Hypothesis Three. Higher levels of the NEO-PI-R trait of Openness will be associated with use of more unconventional therapies.

Hypothesis Four. Individuals who have lower scores on the Compliance and Humility facets of the NEO-PI-R trait of Agreeableness will be likely to have tried a greater number of unconventional therapies.

Hypothesis Five. Participants with higher levels of Internal Locus of Control will manifest greater use of unconventional therapies.

Hypothesis Six. The predictions for the first five hypotheses will be stronger for those who have experienced a Transformational Event in their lives.

Hypothesis Seven. Introduction to Psychology students will more often report having tried one or more unconventional therapy than the general public.

Hypothesis Eight. Among those who have tried one or more unconventional therapies, perceived effectiveness, as measured by the Perceptions of Unconventional Therapies Questionnaire, will be greater for those with higher scores on the personality facets of Compliance and Dutifulness and lower scores on the facet of Modesty. 


\section{CHAPTER II}

\section{METHOD}

The description of the Method employed in this study is organized into the following three sections: 1) Participants; 2) materials; and 3) procedure.

\section{$\underline{\text { Section 1: Participants }}$}

A total of 160 individuals participated in this study. Of these, 102 were students recruited from those enrolled in undergraduate introductory psychology sections at the University of Louisville. The remaining 58 were adults from the local community. Of the 142 Introductory Psychology (IP) students expressing an interest in participating, 105 were recruited. Data from three students were excluded due to non-compliance with instructions, leaving a total of 102. Those who signed Informed Consent forms and participated in the study were given research credit vouchers to partially fulfill course requirements.

The remaining 58 participants were recruited from the general population (GP) in the Louisville area. They were recruited through local area churches, local area businesses, and the University of Louisville. Of the 61 who volunteered to participate, 58 provided Informed Consent and useable protocols. These participants received no direct compensation, but were entered in a lottery drawing with a $\$ 100$ award.

While this combination of participants did not form a systematically stratified sample, the combination of the younger IP and older GP participants was carried out as a way of surveying a broad sample of the local population that would be representative of 
dominant demographic categories including age, gender, and race/ethnicity.

\section{$\underline{\text { Section 2: Materials }}$}

The instruments used in this study consisted of five self-report measures, listed and described here (copies of measures, except the NEO-PI-R, are found in Appendices B through F):

- $\quad$ Background Information Questionnaire (BIQ; unpublished) developed for this study

- $\quad$ NEO-PI-R Personality Inventory, Form S (Costa \& McCrae, 1992)

- $\quad$ Locus of Control Scale (LOC; Levenson, 1973a, 1973b)

- $\quad$ Balanced Inventory of Desirable Responding Scale (BIDR-40; Paulhus \& Reid, 1991), Self-Deception (SD) and Impression Management (IM) subscales only

- $\quad$ Perceptions of Unconventional Therapies Questionnaire (PUTQ; unpublished) developed for this study

The instruments are described below.

Background Information Questionnaire 
The BIQ (Appendix B) surveys demographic information including age, gender, and race, and health status (primary medical conditions). In addition, it includes a multipart item questioning whether or not the person has experienced a 'transformational event,' defined as an experience which altered how the individual thought about life and approached daily activities. Age, race, medical conditions, and transformational events have been found to be associated with the prevalence and patterns of UT use (Astin, 1998; Eisenberg et al., 1993, 1998). Items developed for the questionnaire were adapted from Eisenberg et al. (1993) and Astin (1998).

NEO-PI-R

Form S of the NEO-PI-R (Costa \& McCrae, 1992) was used in this study. The NEO-PI-R is a 240 item forced-choice self-report instrument based on a five-point Likert-type scale. Scores on each of five personality domains (factors) are constructed based on 48 items: Neuroticism, Extraversion, Openness, Agreeableness, and Conscientiousness. Each domain is further subdivided into six facet scales comprised of eight items each. The NEO domain and facet scores were used to test Hypotheses One through Four and Eight.

Reliability and validity. The NEO-PI-R shows adequate strength in reliability and validity for the evaluation of personality factors. For the five personality domains, internal consistency alphas ranged from .86 (Agreeableness) to .92 (Neuroticism). Alphas for the 30 individual facets ranged from .56 (Tender-mindedness) to .81 (Depression), with all facets except Tender-mindedness, Actions, and Compliance at .62 or above (Costa \& McCrae, 1992). Test-retest reliabilities ranged from .63 to .81 for the five domain scales and .51 to .82 for the facet scales (Costa \& McCrae, 1992).

Construct validity of the domain and facet scales is supported by convergent 
validity within scales and strong divergent validity with items in other domains and facets (Costa \& McCrae, 1992). Convergent validity of the five factors and thirty facets has been demonstrated by correlations with other instruments with similar constructs, including Eysenck's scales (McCrae \& Costa, 1985), the Minnesota Multiphasic Personality Inventory (Costa, Busch, Zonderman, \& McCrae, 1986), the State-Trait Personality Inventory (Costa \& McCrae, 1987), and the Millon Clinical Multiaxial Inventory (Millon, 1983). Discriminant validity has been demonstrated by calculating true discriminant correlations between self-reports on the facet scales in one domain with peer ratings on the facet scales of other domains (Costa \& McCrae, 1992).

\section{Locus of Control}

Levenson's (1973a, 1973b) LOC scale (Appendix C) consists of 24 items scored on a seven-point (0 to 6) Likert-type scale. Each of the three dimensions: "Internal;" "Powerful Others;" and "Chance," referring to perceived control of the individual's environment, contains eight items. These three scales were originally developed to help explain why some people seem to thrive under stress, while others get sick. Each scale is scored separately (see Appendix C for scoring criteria) to find each individual's total levels of internal, powerful others, and chance LOC. It was not intended that this study identify anyone's predominant LOC. The total score for internal LOC was used as the independent variable for Hypothesis Five of this study.

Reliability and validity. The items in this LOC scale were written as a Likert scale to provide for statistical independence among the three subscales. They were written to tap the thoughts and feelings of control of the responders in their own lives, not those of people in general, and worded to reduce the likelihood of responders interpreting any modifiability of the issues in the items. In addition, each item of any subscale has 
one that is highly parallel to it in each of the other subscales (Levenson, 1981).

Levenson (1981) summarized the reliability and validity data of this scale from several studies. These indicated that the subscales have shown internal consistencies from .51 to .79 , split-half reliabilities from .62 to .66 , and test-retest reliabilities of .60 to .79 at one week and .62 to .72 at seven weeks. The Powerful others and Chance subscales were found to be correlated from .41 to .60 . Correlations of each of these with the Internal subscale ranged from -.25 to .19 . In addition, no significant correlation was found between items on this scale and those of a social desirability scale.

\section{Extended Health Values Scale}

The EHVS (Appendix D) is an extension of Lau and associates (1986) scale, the Health Values Scale. This extension increased reliability of the predictions. It contains nine statements about health, which respondents rate using a seven-point Likert-type scale (1 = "strongly disagree;" 7 = "strongly agree"). It was designed to predict an individual's intention to engage in health-promoting behavior. The higher the final score, the greater value the individual places on health.

Reliability and validity. Buckley and colleagues (2001) found good test-retest reliability $(\mathrm{r}=.81)$ and internal consistency (alpha $=.82$ at time one and .79 at time two). In an hierarchical regression analysis, they found Health Value significantly improved the prediction of intention to engage in health-promoting behaviors over the Theory of Planned Behavior (Azjen, 1991) alone.

Balanced Inventory of Desirable Responding-40 
As this study assessed perceptions and behavior patterns that might be considered socially questionable or even undesirable (i.e., the idea of 'unconventional' medical treatment), a measure of social desirability was included. The first 40 items of the BIDR (Appendix E) were administered. These comprise two scales, one a measure of Selfdeception (SD, items 1 - 20), the other Impression Management (IM, items 21 - 40). A seven-point Likert-type response scale is employed to assess item responses (Paulhus \& Reid, 1991).

Reliability and validity. In several studies, the internal consistency reliabilities of the SD and IM scales found alphas from .53 to .73 . Various versions of the BIDR have been used as benchmarks against which other social desirability scales have been measured (e.g., Reid-Seiser \& Fritzsche, 2001; Holden, Starzyk, McLeod, \& Edwards, 2000). In addition, it has also been shown to be useful in cross-cultural research involving European and Asian cultures (Choi, 2001).

Perceptions of Unconventional Therapies Questionnaire (PUTQ)

The PUTQ (Appendix F) was developed for this study to address the primary limitations of earlier UT research noted at the end of Chapter I. It consists of two parts that were used to test the hypotheses and the exploratory analyses of this study. First, it assesses perceptions concerning the functions of 10 specific therapies drawn from categories utilized by Eisenberg and colleagues $(1993,1998)$ in their surveys of UT use. Second, it evaluates the perceived effectiveness of any of these therapies used by respondents. In addition to providing information to test the hypotheses and exploratory analyses of this study, it also provides respondents the opportunity to indicate how expensive they think each UT is relative to the other UT and two conventional therapies.

In Part I, participants are asked to indicate whether or not they are familiar with 
each of the 10 UT. For those with which they are familiar, they are then asked to select one of six statements corresponding most closely to their perception of the primary function of each therapy, and are also provided with space to write in a description. Responses to these items were used for the exploratory analysis of how well the public perception of the use of these therapies matches the NCCAM (2001) major domains.

In Part II of the PUTQ, respondents are asked to a) indicate which of the $10 \mathrm{UT}$ they have actually tried; b) specify the condition(s) for which each was used; and c) assess their effectiveness, the last employing a seven-point Likert-type scale $(1=$ "extremely detrimental;" 4 = "no or neutral effect;" 7 = "extremely effective"). The number of UT actually tried served as the dependent variable for those hypotheses related to personality trait factors and the experience of transformational events (Hypotheses One through Six). Whether they had tried any of the UT served as the dependent variable for the comparison between the IP and GP groups (Hypothesis Seven). This was based on determining simply whether or not respondents had used any of the UT. This value also served as the entry variable for Hypothesis Eight, concerning perceived effectiveness. Perceived effectiveness scores provided the dependent variable for this hypothesis.

\section{$\underline{\text { Section 3: Procedure }}$}

Prior to collecting any data, approval to perform the current study was obtained from the University Human Studies Committee. Study participants were tested by the author either individually or in groups of up to 17. All data were collected, scored, and analyzed by this author. After reviewing and signing the Informed Consent form, participants completed the five assessment measures during a session lasting, on average, between 60 and 90 minutes. 
Raw scores for the NEO-PI-R factors and facets were converted to T-scores in accordance with the NEO-PI-R instruction manual (Costa \& McCrae, 1992). Collegeage norms were used for those under 21 years of age and adult norms were used for all others, regardless of whether the individual was part of the IP or GP sample (p. 7). Unanswered items were given the "Neutral" response score (p. 5). No individual left more than three items blank in any facet.

Scoring the PUTQ required the following adjustment. Blank items (not indicating a function or effectiveness score) were recorded as missing data and these protocols (function: 5 protocols; effectiveness: 3 protocols) were excluded from analyses involving the missing data only.

The BIDR-40 was used in this study to assess whether any tendency toward a socially-desirably response set was significantly related to self-reports of number of therapies tried and perceived effectiveness of those therapies. 


\section{CHAPTER III}

\section{RESULTS}

Results of this study are organized into the following five sections: 1) Power analysis and effect size; 2) sample demographic characteristics; 3) response patterns for study questionnaires; 4) evaluation of the study hypotheses; and 5) exploratory analyses.

\section{$\underline{\text { Section 1: Power Analysis and Effect Size }}$}

A power analysis was conducted to determine the sample size necessary to evaluate the study hypotheses. Based on a procedure described by Cohen (1992), it was determined that a sample size of 160 yielded a power value greater than .80 for a medium

effect size at the .05 level of significance. Each prediction in this study, except for that of Hypothesis Seven, was evaluated using data from the entire sample. Therefore, differences between the Introduction to Psychology student (IP) and general population (GP) sub-samples are reported only as they relate to that hypothesis.

\section{Section 2: Sample Demographic Characteristics}

Background Information Questionnaire (BIQ) 
Data pertaining to demographic factors, health status, and experience of transformational life events were collected using the BIQ, an instrument developed for this study (Appendix B). A breakdown of demographic information by gender, age, and race/ethnicity of this study sample is presented in Table 1, accompanied by values for two previous surveys (Astin, 1998; Eisenberg et al., 1993) for comparison purposes. Those two studies were representative of the general population, except that 18 to 24 year olds were under represented in Astin's sample. A comparison of these three samples reveals the following patterns:

- $\quad$ The current survey is comparatively more detailed, but based on a smaller sample [160 vs. 1035 (Astin) and 1539 (Eisenberg)].

- With respect to gender, this study has a much smaller proportion of males $[22.5 \%$ vs. $48.6 \%$ (Astin) and 52\% (Eisenberg)].

- $\quad$ Concerning age, the present study included individuals in the same general age range as the previous studies [18 to 73 years vs. 18 to over 50 (Astin) and 18 to over 64 (Eisenberg)]. However, it contained a far greater proportion of 18 to 24 year olds [61.9\% vs. $7.9 \%$ (Astin) and $16 \%$ (Eisenberg)], and consequently a much smaller proportion of those in the 25 to 34,35 to 49 , and 50 or older age groups.

- The pattern of racial/ethnic composition was as follows: $77.5 \%$ White; 14.4\% Black; 0.5\% Asian; 1.2\% Hispanic; and 1.9\% 'Other.' The racial/ethnic composition of the three samples, while differing in the representation of specific groups, were similar in the overall proportion of minority representation. 
Overall, the present sample is not considered to be demographically representative of the larger population of individuals who have been surveyed in previous studies of this nature.

Health status and transformational event experience are reported for this sample in Tables 2 and 3. With respect to health status, Table 2 presents the results of the present survey, accompanied by data from the Eisenberg and colleagues (1993) study (Astin. 1998 did not report this information). Overall, 27.5\% of participants in the present study reported having one or more primary medical conditions, compared with $83 \%$ in the Eisenberg and colleagues (1993) study. As shown in Table 3, 54.4\% of participants in the present study reported having experienced a transformational event which altered how they thought about life and approached daily activities, a much larger proportion than reported (18.3\%) by Astin (1998; Eisenberg et al., 1993 did not assess this factor).

\section{Section 3: Response Patterns for Study Questionnaires}

This section presents the general results obtained from each of the following study questionnaires: the NEO-PI-R, LOC, EHVS, BIDR-40, and PUTQ. NEO-PI-R

NEO-PI-R raw scores were first converted to T-scores, which range from 20 to 80 , with a mean of 50 and a standard deviation of 10 . The mean personality factor scores for the current study are presented in Table 4. The mean for each factor was within onehalf standard deviation of 50. Standard deviations for the factors were generally slightly larger than 10 , as might be expected in this small a sample. This procedure was repeated for each of the personality facets of this scale with similar results. Facet means ranged from 46.3 to 53.9 with standard deviations between 9.0 and 12.4 . 
The NEO-PI-R employs two different sets of T-scores, one for individuals under 21 , the other for those 21 or older. This adjustment is made to make scores for those under 21 directly comparable to those of other adults (Costa \& McCrae, 1992). NEO-PI$\mathrm{R}$ protocols were scored in accordance with this procedure, resulting in a group of 88 younger participants and 72 age 21 or greater. An Analysis of Variance test comparing the two groups on each of the five factors revealed no significant differences (Table 5).

Overall, sample results on the NEO-PI-R were similar to those reported for the general population, based on data from Costa and McCrae (1992). Personality factor scores did not vary significantly based on scoring norms used.

\section{Locus of Control}

Levenson (1981) summarized over 20 studies that used the LOC scale. The LOC scale is scored for three factors: 'Internal,' Powerful Other,' and 'Chance' loci of control. In those studies, means for Internal varied between 30 and 40, for Powerful others between 14 and 24, and for Chance between 12 and 29. Each of the three had standard deviations within a range of five to ten scaled score points. Mean LOC scores for this study were: Internal locus, 31.9; Powerful other locus, 15.5; and Chance locus, 16.8 (Table 6).

\section{Extended Health Values Scale}

Mean values for the EHVS are also presented in Table 6. This is a newly developed scale, with limited normative data. Available data based on four samples of undergraduate students totaling 587, reveal mean item scores of between 4.37 and 4.78 (Buckley et al., 2001). The mean item score for the present sample (4.39) falls within this range and is within one-half scale point of the neutral response score. Balanced Inventory of Desirable Responding 
Mean scores for the Self-deception (SD) and Impression management (IM) subscales are also presented in Table 6. The average SD item (4.27) and the average IM item (3.34) scores were clustered around the neutral response value for this scale. They are also similar ( $\mathrm{SD}=4.45$ to $4.64 ; \mathrm{IM}=3.74$ to 4.00$)$ to those reported by Paulhus and Reid (1991).

\section{Perceptions of Unconventional Therapies Questionnaire}

Part I. In Part I of this questionnaire, participants were asked to indicate whether or not they had heard of each of the 10 UT surveyed. For each UT with which they were familiar, they then were asked to respond to descriptors of possible functions of each. The latter information is analyzed in the Exploratory Analyses section.

Overall, there was some variability in terms of familiarity with each of the 10 UT, with a tendency toward a negatively skewed distribution: Whereas no one had heard of fewer than three, ten (6.3\%) reported being familiar with all 10 , and $84.4 \%$ had heard of at least seven. In summary, as shown in Table 7, except for the Ornish diet (8.8\%), the majority of participants were familiar with most of the UT surveyed.

Part II. In Part II, participants reported whether or not they had tried each therapy, for what condition(s) each was used, and how effective each was. Participants had tried between none (11.9\%) and eight (1.3\%) of these, with $87.5 \%$ having tried three or fewer. Table 7 also presents the percentages who had tried each. Aside from Massage (72.5\%), fewer than half had tried any therapy and less than $10 \%$ had tried each of five of them. The conditions for which participants used each UT are presented in Tables 8 through 10. The data for perceived effectiveness is presented below in the Hypothesis Eight subsection. 


\section{Section 4: Evaluation of the Study Hypotheses}

\section{Hypotheses One Through Five}

The first five hypotheses predicted the effect of specific personality variables on the number of UT tried. Specifically, it was predicted that those lower in Neuroticism, Compliance, and Humility and higher in Extraversion, Openness, and Internal LOC would have tried more UT. A regression analysis was performed for the combination of these hypotheses. Independent variables for this analysis were the personality factor Tscores for Neuroticism, Extraversion, and Openness and the personality facet T-scores for Compliance and Humility of the NEO-PI-R (Costa \& McCrae, 1992) as well as the Internal LOC score (Levenson, 1973a, 1973b). The dependent variable for this analysis was the number of different UT tried. The regression coefficient for Openness as well as Pearson correlation coefficients for each of the independent variables is presented in Table 11. Although Extraversion and Openness each showed a significant positive correlation with the number of UT tried, only Openness survived the regression analysis and accounted for only $8.2 \%$ of the variance in number of UT tried. 


\section{Hypothesis Six}

It was predicted that the predictions for the first five hypotheses would be stronger for those who had experienced a transformational event. Having experienced a transformational event had a positive point-serial correlation with the number of UT tried, $\mathrm{r}=.198, \mathrm{p}<.01$. For the sixth hypothesis, the regression analysis was repeated with the same independent and dependent variables, but controlling for the experience of a transformational event. As shown in Table 12, the number of UT tried for those who had reported experiencing a transformational event was still predicted by their Openness scores. The $8.5 \%$ of the variance now explained for those who had experienced a transformational event was not a useful increase from the $8.2 \%$ accounted for when transformational events were not taken into account.

\section{Hypothesis Seven}

Hypothesis Seven predicted that IP participants were more likely to have tried one or more UT than GP participants. The IP and GP sub-samples were used to test this hypothesis. The IP sample $\left(\mathrm{N}_{\mathrm{IP}}=102\right)$ was significantly larger than the GP sample $\left(\mathrm{N}_{\mathrm{GP}}\right.$ $=58), \chi^{2}(1)=12.10, p<.01$. Due to the significant difference in size of the IP and GP groups, a Mann-Whitney U-test was performed for this hypothesis. Membership in IP or GP served as the independent variable and having tried one or more UT served as the dependent. This analysis did not yield results in the direction predicted, $Z=-1.970, p<$ .01. IP participants were not more likely to have tried one or more UT than their GP counterparts. The size of the $\mathrm{Z}$ from this analysis raised the question of whether there was a difference between the groups in the number of UT they had tried. A post-hoc Mann-Whitney U-test revealed that the GP participants had tried significantly more of them, $Z=2.885, \mathrm{p}<.01$. 


\section{Hypothesis Eight}

The eighth and final hypothesis of this study predicted greater perceived effectiveness of UT, among those who had tried one or more, for those with higher scores on Compliance, a facet of Agreeableness, and Dutifulness, a facet of Conscientiousness, and lower scores on the Modesty facet of Agreeableness.

Perceived effectiveness for each UT tried was measured in Part II of the PUTQ.

Of the 141 who had tried one or more UT, two did not report effectiveness ratings. The perceived efficacy score for the remaining 139 was the mean of the perceived effectiveness scores for each UT tried. Overall perceived efficacy and the reported effectiveness for each UT are shown in Table 13. Overall, participants found the therapies tried to have been moderately effective $(M=5.6 ; 1=$ "extremely detrimental," 7 = "extremely effective"). Among the individual UT, Massage $(\mathrm{M}=6.1)$ was rated as most effective and Magnet therapy $(\mathrm{M}=3.8)$, the least.

None of the hypothesized facets had significant correlations with the perceived efficacy for the UT tried (Compliance: $r=-.137$, ns; Dutifulness: $r=-.084$, ns; Modesty: $\mathrm{r}=-.011, \mathrm{~ns})$. 


\section{$\underline{\text { Section 5: Exploratory Analyses }}$}

Past research has extensively examined the prevalence and cost of using UT. However, no basis has been developed for examining: 1) What people think the individual therapies do;2) personality traits associated with the use of the individual therapies; or 3) personality traits associated with greater perceived efficacy of the individual UT tried. Therefore, in addition to testing eight basic hypotheses, this study explored three additional areas. The first analysis assesses the degree of concordance between participants' view of UT and how they are classified by NCCAM (2001). Second, personality patterns associated with having tried each UT were assesses. Third, personality patterns associated with ratings of perceived effectiveness of each therapy were evaluated.

Functional Categories of Unconventional Therapies 
In Part I of the PUTQ (Appendix F), participants were asked to assess, by selecting one of seven choices, the main function of each therapy with which they were familiar. Choices consisted of the five NCCAM (2001) major domains; "conventional medical procedure;" and "other," with instructions to write-in the function. Agreement rates with the NCCAM major domains are presented in Table 14. The proportion of agreement ranged from $30.2 \%$ for Therapeutic touch to $83.4 \%$ for Meditation. For six of the ten therapies, agreement rates with the major domains were over $60 \%$. The only therapies for which the NCCAM major domains were not the most frequently chosen were Therapeutic touch and Yoga. "Manipulative/body-based system" (42.7\%) was chosen more frequently for Therapeutic touch than the NCCAM domain "Energy therapy" (30.2\%). For Yoga, "Manipulative/body-based system" (38.0\%) was picked more often than the combination of the two NCCAM domains "Mind-body intervention" (35.4\%) and "Alternative medical system" (1.3\%). 


\section{Individual Difference Patterns Associated with Specific UT Use}

This was an exploratory analysis to determine possible patterns of individual differences between those who had tried and those who had not tried each of these therapies. For each of the 10 therapies surveyed, the individual difference factors were entered into a stepwise Discriminant Function Analysis (DFA). Having tried or not tried the therapy was the variable to be predicted. All factors identified as significant by the DFA were then entered into a regression analysis to determine the proportion of variance, in having tried the therapy, accounted for by the factors. The analyses for each therapy are now presented. The number who reported having tried each comes from the PUTQ, Part II. The factors indicated, with the associated Wilks' Lambda (WL), were those found by stepwise DFA. The directionality and proportion of variance explained were determined by regression analysis.

Acupuncture. Three factors differentiated the four who had tried this therapy from the 156 who had not: Experiencing a transformational event that led to a health change (HC); and the personality facets of Anxiety and Competence. WL (.903) for these three factors was significant, $\mathrm{F}(3,156)=5.65, \mathrm{p}<.01$; and they accounted for $8.1 \%$ of the variance in having tried this therapy. Those who had experienced $\mathrm{HC}$ and who were lower in Anxiety and Competence were more likely to have tried Acupuncture.

Chiropractic. Forty-three participants reported having tried Chiropractic care. Age, HC, and the personality facets Vulnerability and Positive emotions resulted in a significant WL (.829), $\mathrm{F}(4,155)=7.98, \mathrm{p}<.001$. These factors explained $14.9 \%$ of the variance in having tried this form of therapy. Participants who were older, had experienced HC, and who were lower in Vulnerability and Positive emotions were more apt to have tried Chiropractic care. 
Ginkgo biloba. Twenty-one individuals indicated they had tried Ginkgo biloba. DFA indicated only Age differentiated them from the 139 who had not. WL (.850) was significant, $\mathrm{F}(1,158)=27.90, \mathrm{p}<.001$; and age accounted for $14.5 \%$ of the variance. Those who were older were more likely to have tried Ginkgo biloba.

Hypnosis. The seven who had tried this therapy were differentiated from the 153 who had not by four factors: $\mathrm{HC}$ and the personality facets Altruism, Tender-mindedness, and Order. WL (.886) was significant, $\mathrm{F}(4,155)=4.98, \mathrm{p}<.001$ and these factors explained $9.1 \%$ of the variance in having tried Hypnosis. This therapy was more likely to have been tried by those who had experienced HC, were lower in Altruism, and higher in Tender-mindedness and Order.

Magnet therapy. DFA indicated Age and the personality facets Aesthetics, Order, and Achievement striving differentiated the 11 who had tried Magnet therapy from the 139 who had not, with a significant WL $(.859), F(4,155)=6.37, \mathrm{p}<.001$. Being older, higher in Aesthetics and Order, and lower in Achievement striving accounted for 11.9\% of the variance in determining who was more likely to have tried Magnet therapy.

Massage. One hundred sixteen reported they had tried Massage. The Aesthetics personality facet was the only factor found to differentiate them from the 44 who had not tried this therapy. WL $(.958)$ was significant, $\mathrm{F}(1,158)=7.006, \mathrm{p}<.01$. Being higher in Aesthetics explained 3.6\% of the variance in who was more apt to have tried Massage.

Meditation. The Openness personality domain was the only factor to differentiate the 61 who had tried Meditation from the 99 who had not, resulting in a significant WL (.851), $\mathrm{F}(1,158)=27.65, \mathrm{p}<.001$. Those higher in Openness were more likely to have tried Meditation (14.4\% of the variance explained).

Ornish diet. Only three participants reported having tried this therapy. This was 
not a large enough number to support DFA.

Therapeutic touch. HC and the personality facet Trust differentiated the 10 who had tried Therapeutic touch from the 150 who had not. WL (.928) was significant, $\mathrm{F}(2,157)=6.06, \mathrm{p}<.01$, and $6.0 \%$ of the variance in having tried this therapy was explained by these factors. Those who had experienced $\mathrm{HC}$ and who were higher in Trust were more likely to have tried Therapeutic touch.

Yoga. Fifty-two reported having tried Yoga. Fiver personality facets predicted them from the 108 who had not tried it: 1) Aesthetics; 2) Feelings; 3) Actions; 4) Achievement striving; and 5) Positive emotions. These five factors resulted in a significant WL (.838), F(5,154) $=5.60, \mathrm{p}<.001$, and accounted for $13.5 \%$ of the variance in having tried Yoga. Higher levels of Aesthetics, Actions, and Positive emotions and lower levels of Feelings and Achievement striving were associated with having tried Yoga. 


\section{Individual Difference Patterns Associated with Perceived Benefits from UT}

This was an exploratory analysis to determine possible patterns of individual differences between those who perceived relatively more benefit and those who perceived relatively less benefit from each of the therapies they had tried. For each of the 10 therapies surveyed, the individual difference factors were entered into a stepwise DFA. A dichotomized perceived effectiveness score was the variable to be predicted (lower perceived effectiveness, 'lower' versus higher perceived effectiveness, 'higher'). This dichotomous score was determined by performing a median split of effectiveness scores for each therapy separately. Since the median score for each therapy was associated with a positive or neutral rating, the median score was assigned to the 'higher' group. All factors identified as significant by the DFA were then entered into a regression analysis to determine the proportion of variance in relative perceived effectiveness accounted for by the factors. The analyses for each therapy are now presented. The number who reported effectiveness for each therapy comes from the PUTQ, Part II. The factors indicated, with associated WL, were those found by stepwise DFA. The directionality and proportion of variance explained were determined by regression analysis.

Acupuncture. Each of the four participants who tried Acupuncture provided an effectiveness score. Age and Powerful others LOC differentiated the lower and higher groups and accounted for over $99 \%$ of the variance. WL (.000) was significant, $\mathrm{F}(2,1)=$ $85,352.2, \mathrm{p}<.01$. Older participants who attributed more control in their lives to Powerful others perceived greater effectiveness from Acupuncture.

Chiropractic. Of the 43 who tried Chiropractic care, 42 provided an effectiveness score. Only Powerful others LOC differentiated the groups. It explained $9.8 \%$ of the 
variance and WL $(.880)$ was significant, $\mathrm{F}(1,140)=5.48, \mathrm{p}<.05$. Those who attributed less control in their lives to Powerful others reported greater effectiveness from Chiropractic care.

Ginkgo biloba. Of the 21 who had tried Ginkgo biloba, 20 provided effectiveness scores. Impression management (IM) and the personality facets Modesty and Selfdiscipline predicted $65.2 \%$ of the variance in perceived effectiveness. WL (.293) was significant, $\mathrm{F}(3,16)=12.87, \mathrm{p}<.001$. Participants who engaged in less IM and who were higher in Self-discipline and lower in Modesty perceived greater benefit from Ginkgo biloba.

Hypnosis. Each of the seven participants who had tried Hypnosis provided an effectiveness score. Age and the personality facets Values, Altruism, and Tendermindedness explained $39.9 \%$ of the variance between groups. WL (.000) was significant, $\mathrm{F}(4,2)=1222.25, \mathrm{p}<.001$. Those who were older and who exhibited higher levels of Altruism and lower levels of Values and Tender-mindedness perceived Hypnosis as more effective.

Magnet therapy. All 11 participants who tried Magnet therapy provided effectiveness scores. Age, experiencing a transformational event (XE), experiencing a $\mathrm{XE}$ that led to a reexamination of religious beliefs $(\mathrm{RB})$, the number of primary medical conditions, Chance LOC, and the personality facets Excitement seeking and Feelings accounted for over $99 \%$ of the variance between groups. WL (.001) was significant, $\mathrm{F}(7,3)=335.12, \mathrm{p}<.001$. Younger participants who experienced XE that did not lead to RB, who had fewer primary medical conditions, who perceived less control in their lives being due to Chance, and who had higher levels of Excitement seeking and lower levels of feelings rated the effectiveness of Magnet therapy more positively. 
Massage. Of the 116 who tried this therapy, 114 reported an effectiveness score. Gender, IM, and the personality domain Extraversion explained 9.1\% of the variance between the higher and lower groups. WL $(.885)$ was significant, $\mathrm{F}(3,110)=4.76, \mathrm{p}<$ .01 . Women who were higher in Extraversion and engaged in less IM perceived greater effectiveness from Massage.

Meditation. Fifty-nine of the 61 who had tried Meditation provided effectiveness scores. The personality facets Gregariousness and Ideas predicted $12.0 \%$ of the variance between the higher and lower groups. WL $(.849)$ was significant, $F(2,56)=4.70, \mathrm{p}<.05$. Those higher in Ideas and lower in Gregariousness perceived greater effectiveness from Meditation.

Ornish diet. Too few had tried this therapy to support DFA.

Therapeutic touch. Nine of the ten who had tried Therapeutic touch reported effectiveness. RB, Health Values, and the personality facets Impulsiveness, Feelings, and Modesty predicted over $99 \%$ of the variance between groups. WL (.002) was significant, $\mathrm{F}(5,3)=309.55, \mathrm{p}<.001$. Those who had experienced a transformational event that led to RB, who placed greater value on health, who were higher in Feelings and Modesty, and lower in Impulsiveness perceived more effectiveness from therapeutic touch.

Yoga. Of the 52 who tried Yoga, 51 provided effectiveness ratings. Chance LOC and the personality facets Compliance and Achievement striving accounted for $20.6 \%$ of the variance between groups. WL $(.746)$ was significant, $F(3,47)=5.336, p<.01$. Those who attributed more control in their lives to Chance and who were higher in Compliance and Achievement striving perceived greater benefit from Yoga.

The participants in the current study were representative of the larger population 
with respect to minority racial/ethnic representation, personality variables, locus of control, health values, and desirable responding. Males and those over 25 years of age were under represented. Among the hypothesized relationships between individual difference factors and the UT, higher levels of Openness to new experience predicted $8.2 \%$ of the variance in the number of UT used. None of the hypothesized relationships between these factors and overall perceived efficacy of therapies used were supported. In the first exploratory analysis, participants showed a greater than $60 \%$ agreement rate for six of the ten therapies with NCCAM (2001) for the major function associated with each. The second and third exploratory analyses developed individual difference patterns associated with the use and perceived efficacy of each surveyed UT, with the exception of the Ornish diet. 


\section{CHAPTER IV}

\section{DISCUSSION}

The present study examined three aspects of UT. First, it predicted relationships of specific IDFs with the use and overall perceived effectiveness of a group of 10 specific UT. Second, it explored participants' perceptions of the functions of each of the 10 therapies and compared these to the NCCAM (2001) major domain(s) for each. Third, it explored the relationship of specific IDFs with the use and perceived effectiveness of each of the 10 UT surveyed.

This chapter is divided into seven sections. First, results pertaining to the specific hypotheses are discussed. Second, the exploratory analyses are discussed. Third, a series of auxiliary analyses are presented in the context of a discussion of the effect of health values and desirable responding. Fourth, individual difference factors are examined. Fifth, strengths and weaknesses of the study are reviewed. Sixth, some suggestions for future research are presented. The chapter concludes with a synopsis of where this research fits in the study of complementary and alternative medicine.

\section{$\underline{\text { Section 1: Specific Hypotheses }}$}


Hypotheses One through Six and Eight predicted relationships of IDFs with the number of UT tried and the perceived effectiveness of the therapies that had been used. The first five hypotheses of this study were predictions of IDFs associated with the use of UT. Specifically, it was predicted that those higher in the Extraversion and Openness personality domains, higher in Internal LOC, lower in the Neuroticism personality domain, and lower in the Compliance and Humility personality facets would have tried more of these therapies. Of these factors, only Openness survived regression analysis as a predictor and accounted for $8.2 \%$ of the variance in the number of UT used. Contrary to the sixth hypothesis, having experienced a Transformational event did not significantly improve the predictions of the first five hypotheses. The eighth hypothesis predicted greater perceived effectiveness of the UT that had been used among those higher in the Compliance and Dutifulness personality facets and lower in the Modesty personality facet. None of these relationships were supported.

The seventh hypothesis of the current study predicted that IP participants would have been more likely to have tried one or more UT than GP participants. This hypothesis was not supported. Not only were IP participants not more likely to have tried at least one of the UT, on average, the IP participants had tried fewer of them than their GP counterparts.

This difference between the IP and GP participants, in the number of UT tried, along with the difference in their mean ages suggested that other variables may be predictive, or modifying, of the relationships of IDFs with the number of UT used and the perceived effectiveness of those used. To examine this possibility, post-hoc analyses were done, using $\alpha=.01$, to determine the influence of Age, Health Values, and Desirable Responding. Increasing Age was positively correlated with the number of UT 
tried, $\mathrm{r}=.241, \mathrm{p}<.01$, and negatively correlated with the mean perceived effectiveness of the therapies tried, $r=-.272, p<.01$. The views participants held about the importance of Health, measured by the EHVS, were not significantly correlated with either the number of therapies tried, $r=-.044, \mathrm{~ns}$, or their report of perceived effectiveness, $r=-.036$, ns. The number of therapies used was also not significantly related to either the SD $(r=.042, n s)$ or IM $(r=.144, n s)$ sub-scales of the BIDR-40. In addition, SD was not significantly correlated with perceived effectiveness, $r=-.124$, ns. However, IM had a significant inverse correlation with perceived effectiveness, $r=-.220$, $\mathrm{p}<.01$.

Being older and more open to new experience were associated with the use of more UT. Together, Age and Openness explained $14.3 \%$ of the variance in the number of UT that had been used, a 74\% improvement over Openness alone. Since UT are not typically taught or practiced in U.S. medical schools (Stalker, 1995), they represent approaches to health and healing to which we most likely did not become accustomed as we grew up. The UT are thus therapies that could be considered "new experiences." It makes sense that individuals who have greater levels of the Openness to new experience personality trait would be more likely to have tried more of these new experiences. It also follows that the older a person is, the more opportunity he or she has had to try more things, like UT, which are different.

Being younger and engaging in less impression management were associated with greater perceived effectiveness of UT that had been used. Together, Age and IM accounted for $8.3 \%$ of the variance in perceived effectiveness. Those lower in IM are less concerned with the opinions others have of them. As such, they may be less concerned, than those higher in this IDF, with whether a therapy has been proven 
effective when reporting how well it worked for them. Being older was associated with having tried more of these therapies and perceiving less benefit from them. One possible explanation for this is that, along with the longer opportunity greater age provides to try more therapeutic approaches, the experiences over that greater span of time may bring a more critical view of benefits gained from their use. An additional explanation may be related to the cross-sectional nature of the present study. Older participants may have tried some of the UT some years ago. With wider use of UT in recent years, practitioners may be becoming more proficient and/or users may perceive that they are deriving greater benefit than they did in the past.

The specific hypotheses predicted relationships between IDFs and the group of 10 UT surveyed. The small number of IDFs found to be related to the number of UT used and overall perceived effectiveness supports the argument presented in Chapter I (p. 19). Since the individual UT differ in function and approach, they should be examined individually when looking for individual differences associated with their use.

Otherwise, individual variations associated with the personalized use of each might be lost. That was the purpose of the last two of the three exploratory analyses of the present study.

\section{Section 2: Exploratory Analyses}

Functional Categories of Unconventional Therapies 
The investigation of the perceived functions of the therapies yielded wide variation. For six of the ten therapies surveyed, $60.7 \%$ to $83.4 \%$ of participants who had heard of the therapy identified the NCCAM (2001) major domain(s) for that method as the primary function(s) of that therapy. The much lower percentages for Acupuncture, Ornish diet, Therapeutic touch, and Yoga may represent a combination of factors. First, having heard of a treatment does not require or imply knowing much, or anything, about it. After answering over 300 forced-choice items of other measures, participants may have perceived a requirement to pick one of the options given, even if they had no idea what the function was; and "Don't know" was not a presented choice. Second, the definitions provided for the various functions were purposely kept brief. This was done so the functions and their definitions would fit on the same page of the survey as the questions about them. These may have been so brief that they did not provide sufficient definitions for some participants, or worse, in their brevity the definitions may have confused some. Finally, in the case of the Ornish or reversal diet, only 14 participants reported having heard of it. With this small base, the three rather concrete functions written in while choosing "Other," Diet (2) and Arterial Plaque (1), effectively suppressed the proportion choosing "Biological-based therapy" to $42.9 \%$ from about two-thirds.

Even among the six therapies for which over $60 \%$ of the participants chose the NCCAM (2001) major domains as the main functions, up to $40 \%$ did not. This means that a sizable proportion of participants likely had either a mistaken or poorly defined idea of what these therapies are used for. This presents an important implication for practitioners of these therapies and medical professionals who consider referring patients for these procedures. Those being referred and/or seeking UT treatment should be 
provided with information about the function, potential benefits, and potential risks of the procedure, just as they would for a conventional medical procedure.

\section{Patterns associated with Use and Perceived Efficacy}

IDF patterns associated with the use and perceived efficacy of the 10 individual UT surveyed were explored using discriminant function and regression analyses. Too few participants had tried the Ornish diet to support DFA.

Acupuncture. Participants who had experienced a transformational event that led to a health change and who were lower in the Anxiety and Competence personality facets were more likely to have used Acupuncture. Those who were older and who attributed more control in their lives to Powerful others perceived greater effectiveness from this therapy.

Chiropractic. Older participants who had experienced a transformational life event that led to a health change and who were lower in the Vulnerability and Positive emotions personality facets were more apt to have tried Chiropractic. Among those who had tried it, those who attributed less control in their lives to Powerful others reported greater effectiveness.

Ginkgo biloba. With respect to Ginkgo biloba, older individuals were more likely to have tried it. Greater perceived effectiveness from the use of this supplement was found among those who engaged in less Impression management and who were higher in the Self-discipline and lower in the Modesty personality facets.

Hypnosis. Those who had experienced a transformational event that led to a health change and who were lower in Altruism and higher in Tender-mindedness and Order were more likely to have tried Hypnosis. Being older, exhibiting higher levels of Altruism and lower levels of Values and Tender-mindedness were associated with greater 
perceived effectiveness of this therapy.

Magnet therapy. Participants who were older and who were higher in Aesthetics and Order and lower in Achievement striving were more likely to have tried this UT. Those who were younger, who had experienced a transformational event that did not lead to a reexamination of their religious beliefs, who attributed less control in their lives to Chance, and who had higher levels of Excitement seeking and lower levels of Feelings perceived greater effectiveness from using Magnet therapy.

Massage. Those higher in the personality facet of aesthetics more frequently had tried massage. Women who were higher in the Extraversion personality domain and lower in Impression management perceived greater efficacy from its use.

Meditation. Use of Meditation was associated with higher levels of the personality domain Openness. The Ideas facet was positively associated and the Gregariousness facet was negatively associated with greater perceived effectiveness of Meditation.

Therapeutic touch. Those who had experienced a transformational event that led to a health change and who were higher in the Trust personality facet were more likely to have tried this UT. Greater perceived effectiveness for Therapeutic touch was found among those who had not experienced a transformational event that had led to a reexamination of religious beliefs, who placed higher value on their health, and who were higher in Feelings and Modesty and lower in Impulsiveness.

Yoga. Those higher in the Aesthetics, Actions, and Positive emotions facets and lower in the Feelings and Achievement striving facets were more likely to have tried Yoga. Greater perceived efficacy of Yoga was found for those who attributed more control in their lives to Chance and who were higher in the Compliance and Achievement 
striving personality facets.

The reported IDF patterns for perceived effectiveness should be viewed with particular caution for the following, as so few $(<10 \%$ of the sample) reported effectiveness ratings: Acupuncture (4 individuals, $2.5 \%)$; Hypnosis (7, 4.4\%); Magnet therapy (11, 6.7\%); and Therapeutic touch $(9,5.6 \%)$.

It is important to remember that the patterns developed were exploratory. These need to be tested as predictor variables before they are used. If the patterns found withstand hypothesis testing, the variables associated with having used a UT may provide primary care medical professionals with indications of which patients might be more willing to consider trying a particular therapy. The patterns associated with perceived efficacy may point to which patients are more apt to experience benefit.

\section{Section 3: Auxiliary analyses}

Two relationships were revealed that were not specifically part of this study. Scored on the EHVS showed relatively small, but significant, positive correlations with both the SD $(r=.171, \mathrm{p}<.05)$ and IM $(r=.189, \mathrm{p}<.05)$ sub-scales of the BIDR-40. This seems important since physicians frequently rely on individual self-reports about health-related behaviors of their patients. These correlations suggest that individuals may over-estimate both the value they place on health-related behaviors and their reporting of them in contexts where it may seem appropriate to be health-conscious.

\section{Section 4: Individual Difference Factors}


Participants in this study were all volunteers. Although this was not a formally stratified sample and no specific segment of the population was targeted, the recruitment of people from local churches, local businesses, and the university was done in an attempt to build a sample broader than undergraduate freshmen and sophomores that had significant minority representation. Although some IP participants expressed an interest in the UT aspect of the study, most appeared motivated by the experimental credits they received for course credit. Among GP participants, many indicated an interest in UT and few seemed attracted by the prospect of the monetary drawing.

This sample was drawn from a single Midwestern metropolitan area; earlier studies (e.g., Astin, 1998; Eisenberg et al., 1993, 1998) were more broadly based. The present sample was younger and had appreciably greater female representation than the U.S. population or the samples from those earlier studies. However, it did contain a similar level of minority representation.

A much smaller proportion of participants in this study reported having one or more primary medical condition than earlier studies (e.g., Eisenberg et al., 1993). Given the relative youth of the present sample and the trend toward more frequent health problems with age, this is not surprising. A point-biserial correlation showed that having one or more medical condition was positively correlated with age in this sample, $r=.279$, $\mathrm{p}<.01$. A Pearson correlation also showed that age and the number of primary medical conditions reported were positively correlated, $\mathrm{r}=.330, \mathrm{p}<.01$. Older participants were more apt to report having a primary medical condition and tended to have more of them.

Participants in the present study also reported having experienced transformational events at a rate of about three times that found by Astin (1998). The reason for this is not clear. Wording of the question about having experienced such an 
event was similar in the two studies and neither study requested specific information about these events. The greater proportion of younger people in the present sample does not explain the difference either: a point-biserial correlation showed that older participants were significantly more likely to have experienced a transformational event, $\mathrm{r}=.258, \mathrm{p}<.01$. One possible reason for this difference is that data for the present study were collected during the period from four to seven months after the terrorist attacks on the U.S. of September 11, 2001. Participants may have experienced the events of that day as a transformational event.

Other researchers (Astin, 1998; Astin et al., 2000; Eisenberg et al., 1993, 1998; Flaherty et al., 2001; Foster et al., 2000; Millar, 1997; Paramore, 1997) have examined the prevalence of UT use and its association with one or more of the demographic variables of age, sex, race/ethnicity, medical conditions, and transformational events. The major contributions of this study are the relationships developed between specific personality factors and 1) the use of individual UT; and 2) the perceived efficacy of those therapies. It was therefore important that the participants in this sample be reasonably representative of the personality variables used as predictors. As presented in Chapter IV: Results, this was the case.

On the NEO-PI-R (Costa \& McCrae, 1992), the sample mean scores for each of the five personality factors and thirty personality facets were within one-half standard deviation of that reported for the standardization sample. For LOC, the sample means and standard deviations for each scale were within the range found by previous researchers (Levenson, 1981). Mean item scores for the present sample on the EHVS (Buckley et al., 2001) and on the SD and IM sub-scales of the BIDR-40 (Paulhus \& Reid, 1991) were also in the range found in previous research. 
To explore how well study participants' perceptions of the functions of the surveyed UT fit with the NCCAM (2001) domains, it was important that the therapies surveyed have a broad enough base of exposure to be at least moderately well known. This was the case for all but the Ornish (reversal) diet, of which only $8.8 \%$ of respondents reported being familiar. Moreover, a sufficient number of respondents need to have tried each UT (PUTQ, Part II) to explore personality patterns associated with the use and perceived efficacy of each. Again, the Ornish diet was the exception, where too few had tried it to support DFA.

\section{Section 5: Strengths and Limitations}

This study had several strengths. First and foremost, it was the first to examine how a wide range of personality variables are associated with the use and perceived efficacy of individual forms of UT. In addition, it contained a large sample with good minority representation and many women; women and minorities have frequently been under represented in health research. The sample was not limited to Introductory Psychology students and, although it was skewed toward younger individuals, it included adults in each decade of life from their teens through their seventies. The individual personality variables of the participants were consistent with that expected in the population.

The personality measures used are well researched and appropriate for the general population. They tap the five generally agreed upon personality factors (NEO-PI-R) and perceived control (LOC), a factor in how well stress is handled. The BIDR-40 provided a check on whether the perceived effectiveness ratings were associated with desirable responding. In addition, the therapies surveyed by the PUTQ represented all five of the National Center for Complementary and Alternative Medicine (2001) major domains as 
well as two conventional medical procedures.

Like most endeavors, this study also had its share of limitations. First, as already noted, the age distribution of participants was skewed toward those who are younger. Second, the sample was approximately three-quarters female. These both reduce the external generalizability of results. Third, too few participants had tried the Ornish diet (3) to support the IDF exploratory analyses for it. Fourth, the dependent measure for predicting use of the UT was the total number of these therapies each participant had tried. This method of measurement did not differentiate between therapies which had been used only once and those used multiple times or on an on-going basis.

\section{Section 6: Suggestions for Future Research}

Several suggestions for future research surrounding the relationship between individual difference factors and the use and perceived efficacy of unconventional therapies are apparent from this study. First, the development of patterns associated with the use and perceived effectiveness of the surveyed therapies surveyed was exploratory. These patterns need to be tested as predictors. Second, additional research into the patterns associated with those who have tried the therapies should account for differences between those tried only once or a few times and those used frequently or on an on-going basis. Third, for further examination of the patterns associated with the perceived effectiveness of the individual therapies, it would be worthwhile to specifically recruit individuals who had tried each of them as participants in future studies. Fourth, when individual difference patterns have been successfully tested for therapies, research needs to be conducted to determine how to make this an efficiently useful tool for primary care medical professionals.

\section{$\underline{\text { Section 7: Conclusion }}$}


Past research of the unconventional therapies has generally focused on prevalence, demographic patterns of use, monetary expenditures, and associations with primary medical conditions. These have been studies with respect to broad classes of the therapies. Research has also begun looking at the outcome efficacy and mechanisms of change for some specific therapies. The hypotheses of this study were developed to predict the use and perceived effectiveness of the group of 10 specific therapies surveyed. The 10 therapies sampled each of the NCCAM (2001) defined major domains and the predictions were based on more specific individual differences than past studies.

Although most of the hypotheses were not supported, this study provides a starting point for further examination of these areas. The major contributions of the present study were the in-depth exploratory analyses of individual difference variables associated with the use and perceived efficacy of the specific unconventional therapies surveyed. 


\section{REFERENCES}

American Medical Association Council on Medical Education. (1997). Encouraging medical student education in complementary health care practices. Chicago, IL: American Medical Association.

Astin, J. A. (1998). Why patients use alternative medicine: Results of a national survey. Journal of the American Medical Association, 279(19), 1548-1553.

Astin, J.A., Pelletier, K.R., Marie, A., \& Haskell, W.L. (2000). Complementary and alternative medicine use among elderly persons: One-year analysis of a Blue Shield Medicare supplement. Journal of Gerontology, 55A(1), M4-M9.

Azjen, I. (1991). The theory of planned behavior. Organizational Behavior and Human Decision Processes, 50, 179-211.

Baile, W.F., Bigelow, G., Burling, T., Rand, C., Gottlieb, S., Jerome, A., \& Kolodner, K. (1984). Predictors of smoking status six months after myocardial infarction (MI). Psychosomatic Medicine, 46, 285.

Baime, M.J. (1999). Meditation and mindfulness. In W.B. Jonas \& J.S. Levin (Eds.), Essentials of complementary and alternative medicine (pp. 522-536).

Philadelphia: Lippincott Williams \& Wilkins.

Barber, T.X. (1993). Hypnosuggestive approaches to stress reduction: Data, theory, and clinical applications. In P.M. Lehrer \& R.L. Woolfolk (Eds.), Principles and practice of stress management, $2^{\text {nd }}$ ed., pp. 169-204. New York: Guilford.

Benor, D.J. (1999). Spiritual healing. In W.B. Jonas \& J.S. Levin (Eds.), Essentials of complementary and alternative medicine (pp. 369-382). Philadelphia: Lippincott Williams \& Wilkens.

Benson, H. (1975). The relaxation response. New York: William Morrow.

Bernstein, K.S. (2000). The experience of acupuncture for treatment of substance dependence. Journal of Nursing Scholarship, 32(3), 267-272.

Block, K.I. (1999). Nutritional biotherapy. In W.B. Jonas \& J.S. Levin (Eds.), Essentials of complementary and alternative medicine (pp. 490-521). Philadelphia:

Lippincott Williams \& Wilkens. 
Bosworth, H.B., Feaganes, J.R., Vitaliano, P.P., Mark, D.B., \& Siegler, I.C. (2001). Personality and coping with a common stressor: Cardiac catheterization. Journal of Behavioral Medicine, 24(1), 17-31.

British Medical Journal. (1996). Complementary medicine is booming worldwide. Author, 313, 131-133.

Buckley, A.F., Birkimer, J.C., \& Beacham, A.O. (2001). Health value and the theory of planned behavior. Manuscript submitted for publication, University of Louisville.

Carlson, M., Stuart, M., \& Jonas, W. (1997). Alternative medicine instruction in medical schools and family practice residency programs. Family Medicine, 29, 559-562.

Caudill, M.A. (2002). Managing pain before it manages you: Revised edition. New York: The Guilford Press.

Cheung, K.f.M. (1999). Effectiveness of social work treatment and massage therapy for nursing home clients. Research on Social Work Practice, 9(2), 229-247.

Choi, P.Y.L. \& Tweed, A. (1996). The holistic approach in acupuncture treatment: Implications for clinical trials. Journal of Psychosomatic Research, 41(4), 349356.

Choi, S.J. (2001). Acculturation and method bias in reporting of psychological symptoms among first-generation Korean Americans. Dissertation Abstracts International, 61.

Cohen, J. (1992). A power primer. Psychological Bulletin, 112(1), 155-159.

Costa, P.T. (1987). Influence of the normal personality dimension of neuroticism on chest pain symptoms and coronary artery disease. American Journal of Cardiology, 60, 20J-26J.

Costa, P. T., Jr., Busch, C. M., Zonderman, A. B., \& McCrae, R. R. (1986). Correlations of MMPI factor scales with measures of the five-factor model of personality. Journal of Personality Assessment, 50, 640-650.

Costa, P.T., Krantz, D.S., Blumenthal, J.A., \& Furberg, C.D. (1987). Task force 2: Psychological risk factors in coronary artery disease. Circulation, 76(Suppl I), 145-149.

Costa, P. T. \& McCrae, R. R. (1985). The NEO personality inventory manual. Odessa, FL: Psychological Assessment Resources.

Costa, P. T. \& McCrae, R. R. (1987). Personality assessment in psychosomatic medicine: Value of a trait taxonomy. In G. A. Fova \& T. N. Wise (Eds.), Advances in psychosomatic medicine: Vol. 17 Research paradigms in psychosomatic medicine 
(pp. 71-82). Basel Karger.

Costa, P. T. \& McCrae, R. R. (1992). Revised NEO personality inventory (NEO-PI-R) and NEO five-factor inventory (NEO-FFI): Professional manual. Odessa, FL: Psychological Assessment Resources.

Costa, P.T., McCrae, R.R., \& Zonderman, A.B. (1987). Environmental and dispositional influences on well-being: Longitudinal follow-up of an American national sample. British Journal of Psychology, 78(3), 299-306.

Davidson, J.R.T. \& Connor, K.M. (2001). St. John's wort in generalized anxiety disorder: Three case reports. Journal of Clinical Psychopharmacology, 21(6), 635-636.

Davidson, J.R.T., Gadde, K.M., Fairbank, J.A., Krishnan, R.R., Califf, R.M., Binanay, C., et al. (2002). Effect of hypericum perforatum (St. John's wort) in major depressive disorder: A randomized controlled trial. Journal of the American Medical Association, 287(14), 1807-1814.

Dembroski, T.M. \& Costa, P.T. (1987). Coronary prone behavior: Components of the Type A pattern and hostility. Journal of Personality, 55(2), 211-235.

Digman, J.M. \& Takemoto-Chock, N.K. (1981). Factors in the natural language of personality: Re-analysis, comparison, and interpretation of six major studies. Multivariate Behavioral Research, 16, 149-170.

Dog, T.L. (1999). Phytomedicine. In W.B. Jonas \& J.S. Levin (Eds.), Essentials of complementary and alternative medicine (pp. 355-368). Philadelphia: Lippincott Williams \& Wilkens.

Eisenberg, D. M., Davis, R. B., Ettner, S. L., Appel, S., Wilkey, S., Van Rompay, V., \& Kessler, R. C. (1998). Trends in alternative medicine use in the United States, 1990-1997. Journal of the American Medical Association, 280(18), 1569-1575.

Eisenberg, D. M., Kessler, R. C., Foster, C., Norlock, F. E., Calkins, D. R., \& Delbanco, T. L. (1993). Unconventional medicine in the United States: Prevalence, costs, and patterns of use. The New England Journal of Medicine, 328(4), 246-252.

Engle, V.F. \& Graney, M.J. (2000). Biobehavioral effects of therapeutic touch. Journal of Nursing Scholarship, 32(3), 287-293.

Ernst, E., Rand, J.I., \& Stevenson, C. (1998). Complementary therapies for depression: An overview. Archives of General Psychiatry, 55(11), 1026-1032.

The Federation of State Medical Boards of the United States, Inc. (1997). Report on health care fraud. The Special Committee on Health Care Fraud.

Fisher, P. \& Ward, A. (1994). Complementary medicine in Europe. British Medical 
Journal, 309, 107-111.

Flaherty, J.H., Takahashi, R., Teoh, J., Kim, J., Habib, S., Ito, M., \& Matsushita, S. (2001). Use alternative therapies in older outpatients in the United States and Japan: Prevalence, reporting patterns, and perceived effectiveness. Journal of Gerontology, 56A(10), M650-M655.

Fornal, C.A., Metzler, C.W., Mirescu, C., Stein, S.K., \& Jacobs, B.L. (2001). Effects of standardized extracts of St. John's wort on the single-unit activity of seretonergic dorsal raphe neurons in awake cats: Comparisons with fluoxetine and sertaline. Neuropsychopharmacology, 25(6), 858-870.

Foster, D.F., Phillips, R.S., Hamel, M.B., \& Eisenberg, D.M. (2000). Alternative medicine use in older Americans. Journal of the American Geriatrics Society, $48(12), 1560-1565$.

Gevitz, N. (1988). Three perspectives on unorthodox medicine. In N. Gevitz (Ed.), Other healers: Unorthodox medicine in America (pp. 1-28). Baltimore: Johns Hopkins University Press.

Gilbar, O., Iron, G., \& Goren, A. (2001). Adjustment to illness of cancer patients treated by complementary therapy along with conventional therapy. Patient Education and Counseling, 44(3), 243-249.

Gordon, J.S. (1996). Manifesto for a new medicine: Your guide to healing partnerships and the wise use of alternative therapies. Reading, MA: Addison-Wesley.

Hanes, K.R. (2001). Antidepressant effects of the herb salvia divinorum: A case report. Journal of Clinical Psychopharmacology, 21(6), 634-635.

Holden, R.R., Starzyk, K.B., McLeod, L.D., \& Edwards, M.J. (2000). Comparisons among the Holden psychological screening inventory (HPSI), the brief symptom inventory (BSI), and the balanced inventory of desirable responding (BIDR). Assessment, 7(2), 163-175.

Ito, T.Y., Trant, A.S., \& Polan, M.L. (2001). A double-blind placebo-controlled study of ArginMax, a nutritional supplement for enhancement of female sexual function. Journal of Sex and Marital Therapy, 27(5), 541-549.

John, O. P. (1990). The "Big Five" factor taxonomy: Dimensions of personality in the natural language and questionnaires. In L. A. Pervin (Ed.), Handbook of personality theory and research, (pp. 66-100). New York: The Guilford Press.

Jonas, W.B. \& Levin, J.S. (Eds.). (1999). Essentials of complementary and alternative medicine. Philadelphia: Lippincott Williams \& Wilkins.

Kabat-Zinn, J. (1982). An outpatient program in behavioral medicine for chronic pain patients based on the practice of mindfulness meditation: Theoretical 
considerations and preliminary results. General Hospital Psychiatry, 4, 33-47.

Karst, M., Rollnik, J.D., Fink, M., Reinhard, M., \& Pepenbrock, S. (2000). Pressure pain threshold and needle acupuncture in chronic tension-type headache - a doubleblind placebo-controlled study. Pain, 88(2), 199-203.

Lau, R.R., Hartman, K.A., \& Ware, J.E. (1986). Health as a value: Methodological and theoretical considerations. Health Psychology, 5, 25-43.

Levenson, H. (1973a). Activism and powerful others: Distinctions within the concept of internal-external control. Journal of Personality Assessment, 38, 377-383.

Levenson, H. (1973b). Multidimensional locus of control in psychiatric patients. Journal of Consulting and Clinical Psychology, 41, 397-404.

Levenson, H. (1981). Differentiating among internality, powerful others, and chance. In H. M. Lefcourt (Ed.), Research with the locus of control construct: Volume 1: Assessment methods (pp. 15-63). New York: Academic Press.

Linehan, M.M. (1993). Cognitive-behavioral treatment of borderline personality disorder. New York: The Guilford Press.

Lombart, K.G. (1998). Preferences for stress reduction modalities as a function of personality traits. Unpublished master's thesis, University of Louisville.

Lu, D.P., Lu, G.P., \& Kleinman, L. (2001). Acupuncture and clinical hypnosis for facial and head and neck pain: A single crossover comparison. American Journal of Clinical Hypnosis, 44(2), 141-147.

MacLennan, A. H., Wilson, D. H., \& Taylor, A. W. (1996). Prevalence and cost of alternative medicine in Australia. Lancet, 347, 569-573.

McCrae, R. R., \& Costa, P. T., Jr. (1985). Comparison of EPI and psychoticism scales with measures of the five-factor model of personality. Personality and Individual Differences, 6(5), 587-597.

McCrae, R. R., \& John, O. P. (1992). An introduction to the five-factor model and its applications. Journal of Personality, 60(2), 175-215.

Meichenbaum, D. (1993). Stress inoculation training: A 20-year update. In P. M. Lehrer \& R. L. Woolfolk (Eds.), Principles and practices of stress management $\left(2^{\text {nd }} \mathrm{ed}.\right)$ (pp.373-406). New York: The Guilford Press.

Millar, W. J. (1997). Use of alternative health care practitioners by Canadians. Canadian Journal of Public Health, 88(3), 154-158.

Miller, M.J. (1990). The power of the ocean: Another way to diagnosis clients. Counselor 
Education and Supervision, 29, 283-290.

Millon, T. (1983). Millon Clinical Multiaxial Inventory manual (3rd ed.). Minneapolis, MN: Interpretive Scoring Systems.

Muehsam, P.A. (1997). Alternative and complementary medicine special interest group. GEA Correspondent, 10.

National Center for Complementary and Alternative Medicine (2001). For consumers and practitioners: Major domains of complementary and alternative medicine [On-line]. Available: http://nccam.nih.gov/fcp/classify/.

Ornish, D. (1990). Dr. Dean Ornish's program for reversing heart disease. New York: Random House.

Paramore, L. C. (1997). Use of alternative therapies: Estimates from The 1994 Robert Wood Johnson Foundation national access to care survey. Journal of Pain and Symptom Management, 13(2), 83-89.

Paulhus, D.L. \& Reid, D.B. (1991). Enhancement and denial in socially desirable responding. Journal of Personality and Social Psychology, 60(2), 307-317.

Pelletier, K. R., Marie, A., Krasner, M., \& Haskell, W. L. (1997). Current trends in the integration and reimbursement of complementary and alternative medicine by managed care, insurance carriers, and hospital providers. American Journal of Health Promotion, 12(2), 112-122.

Pyevich, D. \& Bogenshutz, M.P. (2001). Herbal diuretics and lithium toxicity. American Journal of Psychiatry, 158(8), 1329.

Reid-Seiser, H.L. \& Fritzsche, B.E. (2001). The usefulness of the NEO PI-R positive presentation management scale for detecting response distortion in employment contexts. Personality and Individual Differences, 31(4), 639-650.

Richard, N.S., Kowaldo, N., \& Gibbs, M.E. (2001). Effects of the Ginkgo biloba extract, $\mathrm{EGb} 761$, on memory formation in day-old chicks. Pharmacology, Biochemistry and Behavior, 69(3-4), 351-358.

Roeschke, J., Wolf, C., Mueller, M.J., Wagner, P., Mann, K., Groezinger, M., \& Bech, S. (2000). The benefit from whole body acupuncture in major depression. Journal of Affective Disorders, 57(1-3), 73-81.

Rotter, J. (1966). A new scale for the measurement of interpersonal trust. Journal of Personality, 35, 651-665.

Sarafino, E. (1994). Stress, Biopsychosocial Factors, and Illness. Health Psychology: Biopsychosocial Interactions ( $2^{\text {nd }}$ ed.), (pp. 122-123). New York: John Wiley \& 
Sons.

Scott, S.C. (1999). Receptivity to Complementary Medical Care in a Sample of College Undergraduates. Unpublished honor's thesis, University of Louisville.

Seligman, M.E.P. (1998a). Building human strength: Psychology's forgotten mission. APA Monitor, 29(1), 2.

Seligman, M.E.P. (1998b). Positive social science. APA Monitor, 29(4), $2 \& 5$.

Seligman, M.E.P. (1998c). What is the "good life"? APA Monitor, 29(10), 2.

Seligman, M.E.P. (1998d). Why therapy works. APA Monitor, 29(12), 2.

Siegler, I.C. \& Brummett, B.H. (2000). Associations among NEO personality assessments and well-being at mid-life: Facet-level analyses. Psychology and Aging, 15(4), 710-714.

Siegler, I.C., Feaganes, J.R., \& Rimer, B.K. (1995). Predictors of adoption of mammography in women under age 50. Health Psychology, 14(3), 274-278.

Skargren, E.I. \& Oeberg, B.E. (1998). Predictive factors for 1-year outcome for low-back and neck pain in patients treated in primary care: Comparison between the treatment strategies chiropractic and physiotherapy. Pain, 77(2), 201-207.

Stalker, D.F. (1995). Evidence and alternative medicine. Mt. Sinai Journal of Medicine, 62, 132-143.

Umezu, T., Sakata, A., \& Ito, H. (2001). Ambulation-promoting effects of peppermint oil and identification of its active components. Pharmacology, Biochemistry and Behavior, 69(3-4), 383-390.

Walston (1976). Mean Health Locus of Control Scales. Journal of Consulting and Clinical Psychology, 44, 580-585.

Weil, A. (1995). Spontaneous healing: How to discover and enhance your body's natural ability to heal itself. New York: Alfred A. Knopf.

Wetzel, M. S., Eisenberg, D. M., \& Kaptchuk, T. J. (1998). Courses involving complementary and alternative medicine at US medical schools. Journal of the American Medical Association, 280(9), 784-787.

Yobimoto, K., Matsumoto, K., Huong, N.T.T., Kasai, R., Yamasaki, K., \& Watanabe, H. (2000). Suppressive effects of Vietnamese ginseng saponin and its major component majonoside-R2 on psychological stress-induced enhancement of lipid peroxidation in the mouse brain. Pharmacology, Biochemistry and Behavior, 66(3), 661-665. 


\section{APPENDICES}

\section{Appendix A}

NEO-PI-R Factors and Facets: A Brief Description

\section{Neuroticism}

Neuroticism $(\mathrm{N})$ is operationalized as a general disposition to feel negative affect including embarrassment, guilt, fear, anger, disgust, and sadness. Low scorers on $\mathrm{N}$ tend to be emotionally stable, even-tempered, relaxed, and calm, whereas high scorers tend to have less impulse control and less effective stress coping strategies (Costa \& McCrae, 1992; Miller, 1990). The six facets of N are: Anxiety, Angry Hostility, Depression, SelfConsciousness, Impulsiveness, and Vulnerability.

'Anxiety' is the first facet of N. It is a measure of apprehensiveness, fearfulness, nervousness, tenseness, and proneness to worry. The next, 'Angry Hostility,' is a measure of proneness to experience anger, bitterness, and frustration. 'Depression' is a measure of proneness to experience depressive affect. 'Self-Consciousness' is a measure of self-perceptions of inferiority, sensitivity to slurs, and interpersonal discomfort. 'Impulsiveness' is a measure of individual inability to control urges, not a measure of risk-taking or spontaneity. The final facet of $\mathrm{N}$, 'Vulnerability,' is a measure of perceived inability to cope with stressful situations (Costa \& McCrae, 1992). Extraversion 
Extraversion (E) is operationalized as sociability, assertiveness, activity, energy, and optimism. High scorers are usually cheerful, experience positive emotions, and seek stimulation and excitement, whereas those with low scores often prefer to be alone and tend to be even-paced, reserved, and independent. From this conceptualization, introversion is the absence of Extraversion, not the polar opposite of Extraversion (Costa \& McCrae, 1992; Miller, 1990). The six facets of E are Warmth, Gregariousness, Assertiveness, Activity, Excitement-Seeking, and Positive Emotions.

The first facet under $\mathrm{E}$ is 'Warmth,' a measure of the affection and friendliness of interpersonal intimacy. Those high in Warmth tend to form close attachments easily and genuinely like others. Low scorers tend to be more distant, formal, and reserved in their interpersonal relationships. The next facet, 'Gregariousness,' is a measure of an individual's preference for the company of others, as opposed to being alone. The third facet is 'Assertiveness,' a measure of social ascendancy, dominance, and forcefulness. Next is 'Activity,' a measure of personal tempo and movement. High scorers tend to be energetic, keeping busy in fast-paced lives. Those who score low in Activity tend to be more relaxed and leisurely in their approach to life. The fifth facet in E is 'ExcitementSeeking,' a measure of the need for stimulation and excitement. The final facet is 'Positive Emotions,' a measure of the propensity to experience happiness, love, and other positive emotions. High scorers tend to be optimistic and cheerful while low scorers tend to be less high-spirited (Costa \& McCrae, 1992).

Openness to Experience 
Openness (O) is operationalized as curiosity of the world, both inner and outer, manifested in intellectual curiosity and independence of judgment. Those high in $\mathrm{O}$ tend to experience emotions, both positive and negative, more fervently. Those lower in $\mathrm{O}$ tend to be more conservative, conventional, and traditional, generally having a narrower range and strength of interests (Costa \& McCrae, 1992). The facets of O are Fantasy, Aesthetics, Feelings, Actions, Ideas, and Values.

'Fantasy' is a measure of imagination and fantasy life. High scorers use fantasy to create a vivid internal world to enrich their creative life. Those lower in Fantasy tend to be less imaginative in sticking to the chore at hand. 'Aesthetics' is a measure of the appreciation of beauty and art. While Aesthetics is not a measure of taste or talent, those high in this facet often develop a broader sense of appreciation for and knowledge of things, events, and people. 'Feelings' is the facet that measures the individual's openness to inner emotions and experiences. Those high in feelings tend to value emotions as an important aspect of life. As a result, they tend to better differentiate emotions and experience them more deeply than others. Low scorers in Feelings tend to discount feelings and emotions and display muted affect. 'Actions' is a measure of preference for varied and novel experiences. The 'Ideas' facet is a measure of intellectual curiosity, the willingness and openness to consider and pursue unconventional notions. 'Values,' as a facet, is a measure of the readiness to reexamine values associated with religion, politics, and society. High scorers do not tend to accept authority, tradition, or dogma at face value (Costa \& McCrae, 1992).

Agreeableness 
Agreeableness (A) is operationalized as sympathy toward others and an expectation that others are sympathetic as well. Those who score high in A tend to be trusting, sympathetic, cooperative, and altruistic. Low scorers tend to be egocentric, antagonistic, competitive, disagreeable, callous, and skeptical of others (Costa \& McCrae, 1992). Trust, Straightforwardness, Altruism, Compliance, Modesty (Humility), and Tender-Mindedness are the six facets of Agreeableness.

'Trust' is a measure of the belief in the honesty and good intentions of others. 'Straightforwardness' is a measure of ingenuousness, sincerity, and frankness. Those who score low on this facet tend to be crafty and deceptive in order to manipulate others. The third facet, 'Altruism,' is a measure of concern for the welfare of others. Those who score high in Altruism tend to be considerate, generous, and willing to help others. Those who score low in this facet tend to be reluctant to help others and are often egocentric. 'Compliance' is a measure of deference to others in interpersonal relations. 'Modesty' is a measure of humility, not of confidence or self-esteem. Those who score low in Modesty tend to act superior toward others and are often perceived as being arrogant. The final facet of A is 'Tender-Mindedness,' a measure of concern and sympathy for others. Those who score high on this facet tend to empathize with the needs of others. Those who score low tend to make decisions based on facts and data as opposed to on the basis of human needs (Costa \& McCrae, 1992). 


\section{Conscientiousness}

Conscientiousness (C) is operationalized as the control of impulses. Those high in $\mathrm{C}$ tend to have strong will, determination, and purpose. They are often high career and academic achievers and may tend to be workaholics, compulsively neat, and irritatingly meticulous. Those who score low in $\mathrm{C}$ tend to be more dilatory and less exacting in their pursuits (Costa \& McCrae, 1992; Digman \& Takemoto-Chock, 1981; Miller, 1990). The facets of C are Competence, Order, Dutifulness, Achievement Striving, Self-Discipline, and Deliberation.

The first facet of C, 'Competence,' is a measure of the individual's perceived sense of effectiveness, capability, prudence, and sensibility. Those who score high on Competence view themselves as up to the tasks of daily life. Those who score low on this facet tend to feel inept and unprepared in dealing with life. 'Order' is a measure of organization. 'Dutifulness' is a measure of how much the individual is consciencedriven. Those who score high tend to be fastidiously moral and ethical in their dealings with others. Those who score low on this facet tend to be less reliable and dependable. 'Achievement Striving' is a measure of aspirations and the motivation to achieve them. Those who score high on this facet tend to be driven to succeed with diligence and purpose. Those who score low tend to lack ambition and tend to be content with lower achievement. 'Self-Discipline' is a measure of the capacity to start and complete projects in spite of extraneous influences. 'Deliberation' is a measure of "looking before leaping." Those who score high on Deliberation tend to be deliberate and cautious, thinking things through before proceeding. Those who score low tend to not consider the consequences of their actions and words before engaging in them (Costa \& McCrae, 1992). 


\section{Appendix B}

\section{Background Information Questionnaire}

Please provide the following information about yourself:

Age:

Gender: $\quad$ FemaleMale

Race/Ethnicity: Asian-American

Black

Caucasian

Hispanic

Native American

Other (please specify)

Please list any primary medical condition(s) you have:

Have you experienced a transformational event in your life that altered how you thought

about
life
and
approa
ched
your
daily
activiti
es?


Yes

No

If yes,

-did this eventually lead to a reexamination of your religious beliefs? Yes No -did it eventually lead to a change in your health?

Yes No 


\section{Appendix C \\ Locus of Control*}

Listed on the next few pages are 24 statements. Read each one and indicate how much the statement describes you by circling the number, from 0 to 6 to the right of each statement. "0" indicates that the statement does not describe you at all. "3" indicates that the statement describes you moderately well. "6" indicates that the statement describes you extremely well.

*Scoring:

Internal is the summation of items $1,4,5,9,18,19,21,23$.

Powerful Others is the summation of items 3, 8, 11, 13, 15, 17, 20, 22.

Chance is the summation of items $2,6,7,10,12,14,16,24$ 
This statement describes me:

Not at Moderately Extremely

Statement:

All Well Well

1. Whether or not I get to be a leader

depends mostly on my ability............ $\quad \begin{array}{lllllllll} & 0 & 1 & 2 & 3 & 4 & 5 & 6\end{array}$

2. To a great extent my life is controlled

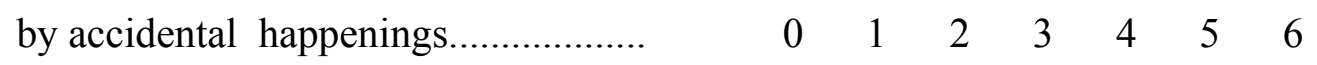

3. I feel like what happens in my life is

$\begin{array}{llllllllll}\text { mostly determined by powerful people... } & & 0 & 1 & 2 & 3 & 4 & 5 & 6\end{array}$

4. Whether or not I get into a car accident

depends mostly a matter on

how good a driver I am...

$\begin{array}{lllllll}0 & 1 & 2 & 3 & 4 & 5 & 6\end{array}$

5. When I make plans, I am almost certain to make them work.

$\begin{array}{lllllll}0 & 1 & 2 & 3 & 4 & 5 & 6\end{array}$

6. Often there is no chance of protecting my

$\begin{array}{lllllllll}\text { personal interests from bad luck happenings } & 0 & 1 & 2 & 3 & 4 & 5 & 6\end{array}$

7. When I get what I want, it's usually

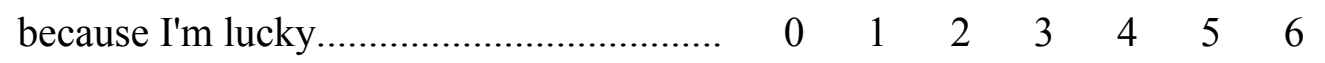

8. Although I might have good ability, I will

not be given leadership responsibility

without appealing to those in positions

of power......................................... $0 \quad \begin{array}{lllllll}1 & 2 & 3 & 4 & 5 & 6\end{array}$ 
This statement describes me:

Statement:

9. How many friends I have depends on how nice a person I am

10. I have often found that what is going to happen will happen

11. My life is chiefly controlled by powerful others

12. Whether or not I get into a car accident is mostly a matter of luck

13. People like myself have very little chance of protecting our personal interests when they conflict with those of strong pressure groups

14. It's not always wise for me to plan too far ahead because many things turn out to be a matter of good or bad fortune.......

15. Getting what I want requires pleasing those people above me..............................

16. Whether or not I get to be a leader depends on whether I'm lucky enough to be in the right place at the right time.......
Not at Moderately Extremely
All
Well
Well

$\begin{array}{lllllll}0 & 1 & 2 & 3 & 4 & 5 & 6\end{array}$

$\begin{array}{lllllll}0 & 1 & 2 & 3 & 4 & 5 & 6\end{array}$

$\begin{array}{lllllll}0 & 1 & 2 & 3 & 4 & 5 & 6\end{array}$

$\begin{array}{lllllll}0 & 1 & 2 & 3 & 4 & 5 & 6\end{array}$

$\begin{array}{lllllll}0 & 1 & 2 & 3 & 4 & 5 & 6\end{array}$

$\begin{array}{lllllll}0 & 1 & 2 & 3 & 4 & 5 & 6\end{array}$

$\begin{array}{lllllll}0 & 1 & 2 & 3 & 4 & 5 & 6\end{array}$

$\begin{array}{lllllll}0 & 1 & 2 & 3 & 4 & 5 & 6\end{array}$ 
This statement describes me:

Statement:

17. If important people were to decide they didn't like me, I probably wouldn't make many

friends

18. I can pretty much determine what will happen in my life.

19. I am usually able to protect my personal interests

20. Whether or not I get into a car accident depends mostly on the other driver..........

21. When I get what I want, it's usually because I worked hard for

it.

22. In order to have my plans work, I make sure that they fit in with the desires of people who have power over

me.

23. My life is determined by my own actions

24. It's chiefly a matter of fate whether or not I have a few friends or many
Not at Moderately Extremely

All Well Well

$\begin{array}{lllllll}0 & 1 & 2 & 3 & 4 & 5 & 6\end{array}$

$\begin{array}{lllllll}0 & 1 & 2 & 3 & 4 & 5 & 6\end{array}$

$\begin{array}{lllllll}0 & 1 & 2 & 3 & 4 & 5 & 6\end{array}$

$\begin{array}{lllllll}0 & 1 & 2 & 3 & 4 & 5 & 6\end{array}$

$\begin{array}{lllllll}0 & 1 & 2 & 3 & 4 & 5 & 6\end{array}$

$\begin{array}{lllllll}0 & 1 & 2 & 3 & 4 & 5 & 6\end{array}$

$\begin{array}{lllllll}0 & 1 & 2 & 3 & 4 & 5 & 6\end{array}$ 
friends.. 


\section{Appendix D}

The Extended Health Values Scale*

Below are some statements about health. Please indicate your agreement or disagreement with each statement by circling the number that best describes how you feel about the statement. Use the scale from (1) Strongly Disagree to (7) Strongly Agree.

\section{Strongly Strongly \\ Disagree Neutral Agree}

1) If you don't have your health you don't have anything. $\quad \begin{array}{lllllll}1 & 2 & 3 & 4 & 5 & 6 & 7\end{array}$

2) There are many things I care about more than my health. $\begin{array}{lllllll}1 & 2 & 3 & 4 & 5 & 6\end{array}$

3) Good health is of only minor importance in a happy life. $\begin{array}{lllllll}1 & 2 & 3 & 4 & 5 & 6 & 7\end{array}$

4) There is nothing more important than good health. $\quad \begin{array}{lllllll}1 & 2 & 3 & 4 & 5 & 6 & 7\end{array}$

5) Being in good health is a top priority for me. $\quad \begin{array}{lllllll}2 & 2 & 3 & 4 & 5 & 6 & 7\end{array}$

6) You cannot be happy unless you have good health. $\quad \begin{array}{lllllll}1 & 2 & 3 & 4 & 5 & 6 & 7\end{array}$

7) Other things are more important to me than good health. $\begin{array}{llllllll}1 & 2 & 3 & 4 & 5 & 6 & 7\end{array}$

8) People are too concerned about being healthy. $\quad \begin{array}{lllllll} & 2 & 3 & 4 & 5 & 6 & 7\end{array}$

9) If you don't have good health you can't live a full life. $\quad \begin{array}{llllllll}1 & 2 & 3 & 4 & 5 & 6 & 7\end{array}$

* = Items 2, 3, 7, and 8 are reverse-scored. 


\section{Appendix E}

\section{Balanced Inventory of Desired Responding - 40*}

Answer each of the following questions as honestly as you can. Use a scale from (1) Not true to (7) Very true, telling how true the item is for you.

$\begin{array}{ll}\text { Not } & \text { Very } \\ \text { True } & \text { True }\end{array}$

1. My first impressions about people usually turn out to be right. $\quad \begin{array}{lllllll}1 & 2 & 3 & 4 & 5 & 6 & 7\end{array}$ 2. It would be hard for me to break any of my bad habits. $\quad \begin{array}{lllllll}1 & 2 & 3 & 4 & 5 & 6\end{array}$

3. I don't care to know what other people really think of me. $\quad \begin{array}{lllllll}1 & 2 & 3 & 4 & 5 & 6\end{array}$

4. I have not always been honest with myself. $\quad \begin{array}{lllllll}2 & 2 & 3 & 4 & 5 & 6 & 7\end{array}$

5. I always know why I like things. $\quad 1 \begin{array}{llllll}2 & 3 & 4 & 5 & 6\end{array}$

6. I don't know what my major strengths and weaknesses are. $\quad \begin{array}{lllllll}1 & 2 & 3 & 4 & 5 & 6\end{array}$

7. Once I've made up my mind, other people can seldom change $\quad \begin{array}{lllllll}1 & 2 & 3 & 4 & 5 & 6 & 7\end{array}$ my opinion.

8. I am not a safe driver when I exceed the speed limit. $\quad \begin{array}{lllllll}2 & 3 & 4 & 5 & 6\end{array}$

9. I am fully in control of my own fate. $\quad \begin{array}{lllllll}2 & 3 & 4 & 5 & 6 & 7\end{array}$

10. It's hard for me to shut off a disturbing thought. $\quad \begin{array}{lllllll}2 & 3 & 4 & 5 & 6\end{array}$

11. I never regret my decisions. $\quad 1 \begin{array}{llllll}2 & 3 & 4 & 5 & 6\end{array}$

12. I sometimes lose out on things because I can't make up my $\quad \begin{array}{lllllll}1 & 2 & 3 & 4 & 5 & 6\end{array}$ mind soon enough.

13. The reason I vote is because my vote can make a difference. $\quad \begin{array}{lllllll}1 & 2 & 3 & 4 & 5 & 6\end{array}$

14. My parents were not always fair when they punished me. $\quad \begin{array}{lllllll}1 & 2 & 3 & 4 & 5 & 6 & 7\end{array}$

15. I am a completely rational person. $\quad 1 \quad 2 \quad 3 \quad 4 \quad 567$

16. I rarely appreciate criticism. $\quad 1 \begin{array}{llllll}2 & 3 & 4 & 5 & 6 & 7\end{array}$ 
17. My solutions to problems are original and effective.

18. I have sometimes doubted my ability as a sex partner.

$\begin{array}{lllllll}1 & 2 & 3 & 4 & 5 & 6 & 7\end{array}$

19. It's alright with me if some people happen to dislike me.

$\begin{array}{lllllll}1 & 2 & 3 & 4 & 5 & 6 & 7\end{array}$

20. I don't always know the reasons why I do the things I do.

$\begin{array}{lllllll}1 & 2 & 3 & 4 & 5 & 6 & 7\end{array}$

21. I sometimes tell lies if I have to.

$\begin{array}{lllllll}1 & 2 & 3 & 4 & 5 & 6 & 7\end{array}$

22. I never cover up my mistakes.

$\begin{array}{lllllll}1 & 2 & 3 & 4 & 5 & 6 & 7\end{array}$

23. There have been occasions when I have taken advantage of someone.

24. I never swear.

25. I sometimes try to get even rather than forgive and forget.

$\begin{array}{lllllll}1 & 2 & 3 & 4 & 5 & 6 & 7\end{array}$

26. I always obey laws, even if I'm unlikely to get caught.

$\begin{array}{lllllll}1 & 2 & 3 & 4 & 5 & 6 & 7\end{array}$

27. I have never said something bad about a friend behind his

$\begin{array}{lllllll}1 & 2 & 3 & 4 & 5 & 6 & 7\end{array}$ or her back.

28. When I hear people talking privately, I avoid listening.

$\begin{array}{lllllll}1 & 2 & 3 & 4 & 5 & 6 & 7\end{array}$

29. I have received too much change from a salesperson

$\begin{array}{lllllll}1 & 2 & 3 & 4 & 5 & 6 & 7\end{array}$ without telling him or her.

30. I always declare everything at customs.

$\begin{array}{lllllll}1 & 2 & 3 & 4 & 5 & 6 & 7\end{array}$

31. When I was young, I sometimes stole things.

$\begin{array}{lllllll}1 & 2 & 3 & 4 & 5 & 6 & 7\end{array}$

32. I have never dropped litter on the street.

33. I sometimes drive faster than the speed limit.

$\begin{array}{lllllll}1 & 2 & 3 & 4 & 5 & 6 & 7\end{array}$

34. I never read sexy books or magazines.

35. I have done things I don't tell other people about.

$\begin{array}{lllllll}1 & 2 & 3 & 4 & 5 & 6 & 7\end{array}$

36. I never take things that don't belong to me. 
37. I have taken sick-leave from work or school even though

I wasn't really sick.

38. I have never damaged a library book or store merchandise

without reporting it.

39. I have some pretty awful habits.

40. I don't gossip about other people's business.

*Scoring:

Self-Deception: Sum of first 20 items after reverse-scoring even items.

Impression Management: Sum of last 20 items after reverse-scoring odd items. 
Appendix F

Perceptions of Unconventional Therapies Questionnaire - Part I.

1. For each of the therapies listed on this page, indicate: whether you have heard of it (circle Yes) or not heard of it (circle No).

B. For each therapy you answered "Yes" to in part A., circle the one number which you thinks best describes the main function of that therapy (per the following).

1 Alternative Medical System a complete medical system developed independent

of the conventional biomedical approach

2 Mind-Body Intervention.... a technique to facilitate the mind's capacity to

affect bodily functions and symptoms

3 Biological-Based Therapy.... natural and biologically-based interventions and

products which are not part of the conventional

biomedical approach

4 Manipulative/Body-Based System.... based on movement and/or manipulation of the body or parts of the body

5 Energy Therapy.... the use of energy fields within the body or energy

fields from other sources

6 Conventional Medical Procedure.... the conventional biomedical approach

7 Other (If you pick this one, indicate function on blank line provided) 


\begin{tabular}{|c|c|c|c|c|c|c|c|c|c|}
\hline \multirow{3}{*}{$\begin{array}{l}\text { Therapy Type } \\
\text { Acupuncture }\end{array}$} & \multicolumn{9}{|c|}{ A. Have you heard } \\
\hline & \multicolumn{2}{|c|}{ of this therapy? } & \multicolumn{7}{|c|}{ B. Main function of this therapy? } \\
\hline & Yes & No & 1 & 2 & 3 & 4 & 5 & 6 & 7 \\
\hline Beta-Blocker & Yes & No & 1 & 2 & 3 & 4 & 5 & 6 & 7 \\
\hline Chiropractic & Yes & No & 1 & 2 & 3 & 4 & 5 & 6 & 7 \\
\hline Ginkgo Biloba & Yes & No & 1 & 2 & 3 & 4 & 5 & 6 & 7 \\
\hline Hypnosis & Yes & No & 1 & 2 & 3 & 4 & 5 & 6 & 7 \\
\hline Magnet & Yes & No & 1 & 2 & 3 & 4 & 5 & 6 & 7 \\
\hline Massage & Yes & No & 1 & 2 & 3 & 4 & 5 & 6 & 7 \\
\hline Meditation & Yes & No & 1 & 2 & 3 & 4 & 5 & 6 & 7 \\
\hline Open Heart Surgery & Yes & No & 1 & 2 & 3 & 4 & 5 & 6 & 7 \\
\hline Ornish or Reversal Diet & Yes & No & 1 & 2 & 3 & 4 & 5 & 6 & 7 \\
\hline Therapeutic Touch & Yes & No & 1 & 2 & 3 & 4 & 5 & 6 & 7 \\
\hline Yoga & Yes & No & 1 & 2 & 3 & 4 & 5 & 6 & 7 \\
\hline
\end{tabular}




\section{Perceptions of Unconventional Therapies Questionnaire - Part II}

1. For each of the therapies listed below, indicate: whether you have tried it (circle Yes) or not tried it (circle No).

2. For each therapy you answered "Yes" to in part A.,print what condition(s) you used it for (i.e., what you used the therapy to treat, improve, change, etc.).

C. For each therapy you answered "Yes" to in part A., circle the number which you think best describes how effective that therapy was for you (using this scale).

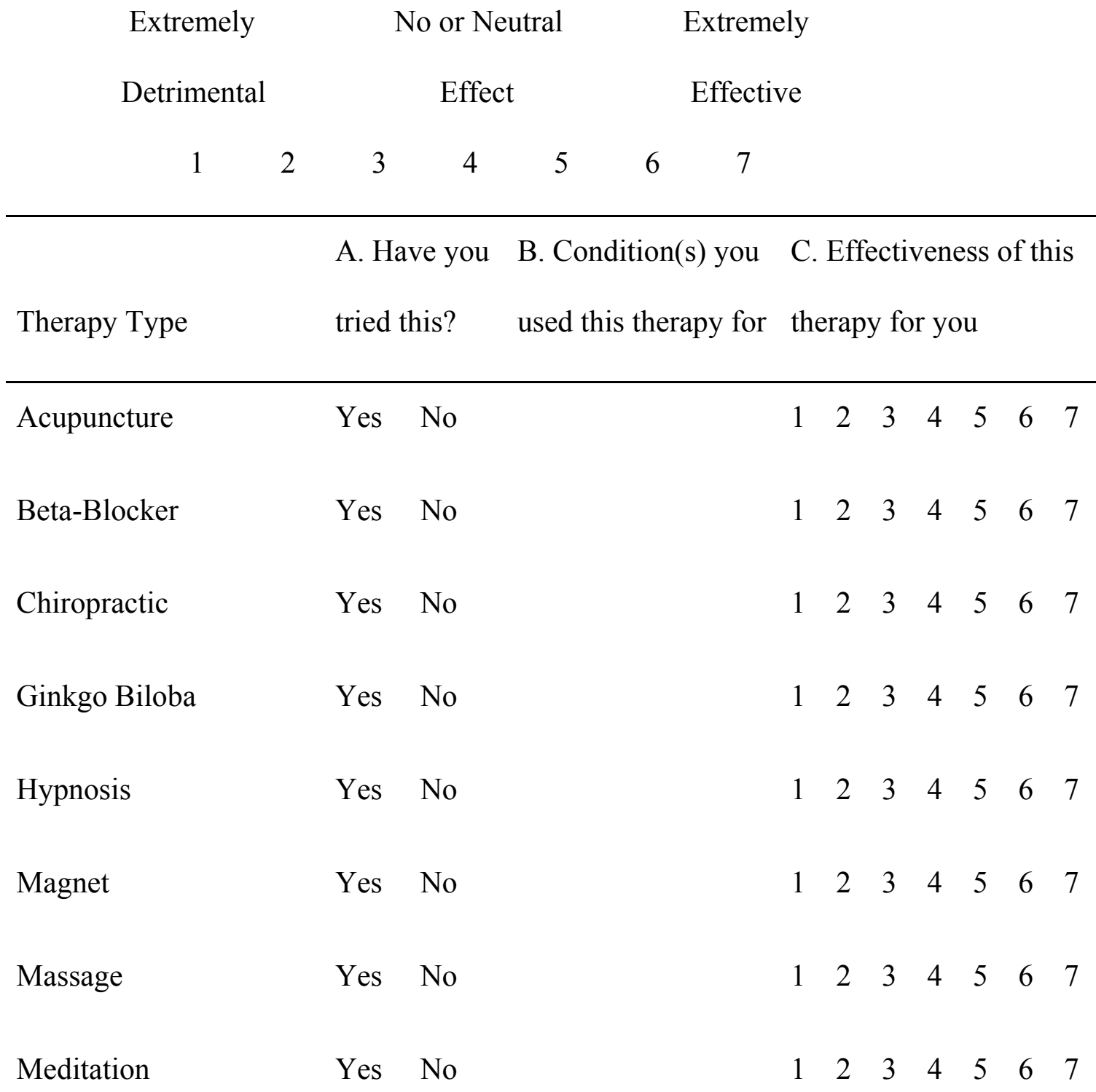




\begin{tabular}{|c|c|c|c|c|c|c|c|c|c|}
\hline Open Heart Surgery & Yes & No & 1 & 2 & 3 & 4 & 5 & & \\
\hline Ornish or Reversal Diet & Yes & No & 1 & 2 & 3 & 4 & 5 & & \\
\hline Therapeutic Touch & Yes & No & 1 & 2 & 3 & 4 & 5 & & \\
\hline Yoga & Yes & No & 1 & 2 & 3 & 4 & 5 & & \\
\hline
\end{tabular}




\section{Perceptions of Unconventional Therapies Questionnaire - Part III}

1. For each of the therapies listed below that you have heard of, indicate how expensive you think it would be compared to the others on the list (according to this scale).

\begin{tabular}{ccccccc} 
Very & Somewhat & \multicolumn{2}{c}{ Somewhat } & Very \\
Inexpensive & Inexpensive & Expensive & Expensive \\
1 & 2 & 3 & 4 & 5 & 6 & 7
\end{tabular}

A. Expense of this therapy

Very Somewhat Somewhat Very

Therapy Type Inexpensive Inexpensive Expensive Expensive

\begin{tabular}{|c|c|c|c|c|c|c|c|}
\hline Acupuncture & 1 & 2 & 3 & 4 & 5 & 6 & 7 \\
\hline Beta-Blocker & 1 & 2 & 3 & 4 & 5 & 6 & 7 \\
\hline Chiropractic & 1 & 2 & 3 & 4 & 5 & 6 & 7 \\
\hline Ginkgo Biloba & 1 & 2 & 3 & 4 & 5 & 6 & 7 \\
\hline Hypnosis & 1 & 2 & 3 & 4 & 5 & 6 & 7 \\
\hline Magnet & 1 & 2 & 3 & 4 & 5 & 6 & 7 \\
\hline Massage & 1 & 2 & 3 & 4 & 5 & 6 & 7 \\
\hline Meditation & 1 & 2 & 3 & 4 & 5 & 6 & 7 \\
\hline Open Heart Surgery & 1 & 2 & 3 & 4 & 5 & 6 & 7 \\
\hline
\end{tabular}




\begin{tabular}{lccccccc} 
Ornish or Reversal Diet & 1 & 2 & 3 & 4 & 5 & 6 & 7 \\
Therapeutic Touch & 1 & 2 & 3 & 4 & 5 & 6 & 7 \\
Yoga & 1 & 2 & 3 & 4 & 5 & 6 & 7 \\
\hline
\end{tabular}




\section{Appendix G}

Tables

Table 1

Demographic Information of This and Past Studies

\begin{tabular}{|c|c|c|c|}
\hline & This Study & Eisenberg (1993) & Astin (1998) \\
\hline & $\mathrm{N}=160$ & $\mathrm{~N}=1539$ & $\mathrm{~N}=1035$ \\
\hline \multicolumn{4}{|l|}{ Sex } \\
\hline Female & 77.5 & 48 & 51.4 \\
\hline Male & 22.5 & 52 & 48.6 \\
\hline \multicolumn{4}{|l|}{ Age in years } \\
\hline $18-24$ & 61.9 & 16 & 7.9 \\
\hline $25-34$ & 9.4 & 23 & 21.5 \\
\hline $35-49$ & 13.8 & 27 & 34.8 \\
\hline 50 and older & 15.0 & 34 & 35.9 \\
\hline \multicolumn{4}{|l|}{ Race/Ethnicity } \\
\hline White & 77.5 & 82 & 79.5 \\
\hline Black & 14.4 & 9 & 8.3 \\
\hline Asian & 5.0 & 1 & 0.9 \\
\hline Hispanic & 1.2 & 6 & 7.5 \\
\hline Other & 1.9 & 2 & 3.8 \\
\hline
\end{tabular}

Note. Values reported are the percentages from the respective samples. 


\section{Table 2}

Number of Primary Medical Conditions Reported in This and Previous Study

\begin{tabular}{lcc}
\hline & This Study & Eisenberg (1993) \\
& $\mathrm{N}=160$ & $\mathrm{~N}=1539$ \\
\cline { 2 - 3 } & & 17 \\
None & 18.8 & 19 \\
2 & 6.9 & 16 \\
3 or more & 1.9 & 48 \\
At least 1 & 27.5 & 83 \\
\hline
\end{tabular}

Note. Values reported are the percentages from the respective samples. 
Table 3

$\underline{\text { Transformational Events Experienced }}$

\begin{tabular}{lcc}
\hline & This Study & Astin (1998) \\
& $\mathrm{N}=160$ & $\mathrm{~N}=1035$ \\
\cline { 2 - 3 } Experienced Transformational Event & 54.4 & 18.3 \\
Transformational Event led to reexamination of beliefs & 34.4 & a \\
Transformational Event led to health change & 25.6 & a \\
\hline
\end{tabular}

Notes. Values reported are percentages of the sample.

${ }^{a}$ Not reported in this study. 
Table 4

Mean T-scores for Each NEO-PI-R Personality Factor

\begin{tabular}{lcccc}
\hline & Mean & Standard & Minimum & Maximum \\
& Score & deviation & score & score \\
\cline { 2 - 5 } Neuroticism & 49.8 & 11.4 & 20 & 80 \\
Extraversion & 52.6 & 11.6 & 20 & 80 \\
Openness & 52.8 & 9.9 & 29 & 78 \\
Agreeableness & 49.9 & 11.1 & 20 & 80 \\
Conscientiousness & 46.4 & 10.8 & 20 & 72 \\
\hline
\end{tabular}

Note. Sample contained 160 
Table 5

Analysis of Variance Comparison of NEO-PI-R Factor T-scores Based on Scoring Norms $\underline{\text { Used }}$

\begin{tabular}{lcc}
\hline & $F(158)$ & Significance \\
\cline { 2 - 3 } Neuroticism & 2.862 & .093 \\
Extraversion & 2.679 & .104 \\
Openness & 1.545 & .216 \\
Agreeableness & 2.710 & .102 \\
Conscientiousness & & .746 \\
\hline
\end{tabular}

Notes. Number in under 21 group $=88$. Number in 21 or older group $=72$. Size difference between groups: $\chi^{2}(1)=1.60$, ns. 
Table 6

$\underline{\text { Participant Scores on Locus of Control Scales, Extended Health Values Scale, and }}$ Balanced Inventory of Desirable Responding

\begin{tabular}{|c|c|c|c|c|}
\hline & $\begin{array}{l}\text { Mean } \\
\text { score }\end{array}$ & $\begin{array}{l}\text { Standard } \\
\text { deviation }\end{array}$ & $\begin{array}{l}\text { Low } \\
\text { score }\end{array}$ & $\begin{array}{l}\text { High } \\
\text { score }\end{array}$ \\
\hline \multicolumn{5}{|l|}{ Locus of Control $^{\mathrm{a}}$} \\
\hline Internal & 31.9 & 6.3 & 13 & 48 \\
\hline Powerful Others & 15.5 & 7.5 & 0 & 34 \\
\hline Chance & 16.8 & 6.9 & 0 & 35 \\
\hline Extended Health Values ${ }^{b}$ & 39.5 & 8.9 & 14 & 61 \\
\hline \multicolumn{5}{|l|}{ BIDR-40 } \\
\hline Self-deception & 85.4 & 13.7 & 9 & 120 \\
\hline Impression management & 76.8 & 16.7 & 31 & 115 \\
\hline
\end{tabular}

Notes. All measures were scored on seven-point Likert-type scales.

aScale values: $\mathrm{O}=$ "not at all;" $6=$ "extremely well." b' Scale values: 1 = "strongly disagree;" 7 = "Strongly agree." "Scale values: 1 = "not true;" 7 = "very true." 
Table 7

Percent of Sample Having Heard of and Tried Each Surveyed Unconventional Therapy

\begin{tabular}{|c|c|c|}
\hline & Heard of therapy & Tried therapy \\
\hline Massage & 100.0 & 72.5 \\
\hline Meditation & 98.1 & 38.1 \\
\hline Yoga & 98.8 & 32.5 \\
\hline Chiropractic & 98.1 & 26.9 \\
\hline Ginkgo biloba & 66.9 & 13.1 \\
\hline Magnet & 63.1 & 6.9 \\
\hline Therapeutic touch & 60.0 & 6.3 \\
\hline Hypnosis & 98.8 & 4.4 \\
\hline Acupuncture & 90.6 & 2.5 \\
\hline Ornish diet & 8.8 & 1.9 \\
\hline
\end{tabular}

Note. Values are percent of 160 participant sample. 
Table 8

Conditions for Which Acupuncture, Chiropractic, and Ginkgo Biloba Were Used

\begin{tabular}{|c|c|c|}
\hline & Conditions treated & Percent of Sample \\
\hline \multirow[t]{2}{*}{ Acupuncture } & Injuries & 0.6 \\
\hline & Headaches & 0.6 \\
\hline \multirow[t]{7}{*}{ Chiropractic } & Back & 15.6 \\
\hline & Neck & 3.1 \\
\hline & Arthritis & 1.2 \\
\hline & Headaches & 1.2 \\
\hline & Abdomen & 0.6 \\
\hline & Stress & 0.6 \\
\hline & Other treatment & 5.0 \\
\hline \multirow[t]{5}{*}{ Ginkgo biloba } & Memory & 5.0 \\
\hline & Energy & 3.1 \\
\hline & Metabolism & 0.6 \\
\hline & Aging & 0.6 \\
\hline & Other & 1.2 \\
\hline
\end{tabular}

Notes. Sample $\mathrm{N}=160$. Some participants reported multiple conditions for therapies used. 
Table 9

Conditions for Which Hypnosis, Magnet Therapy, and Massage Were Used

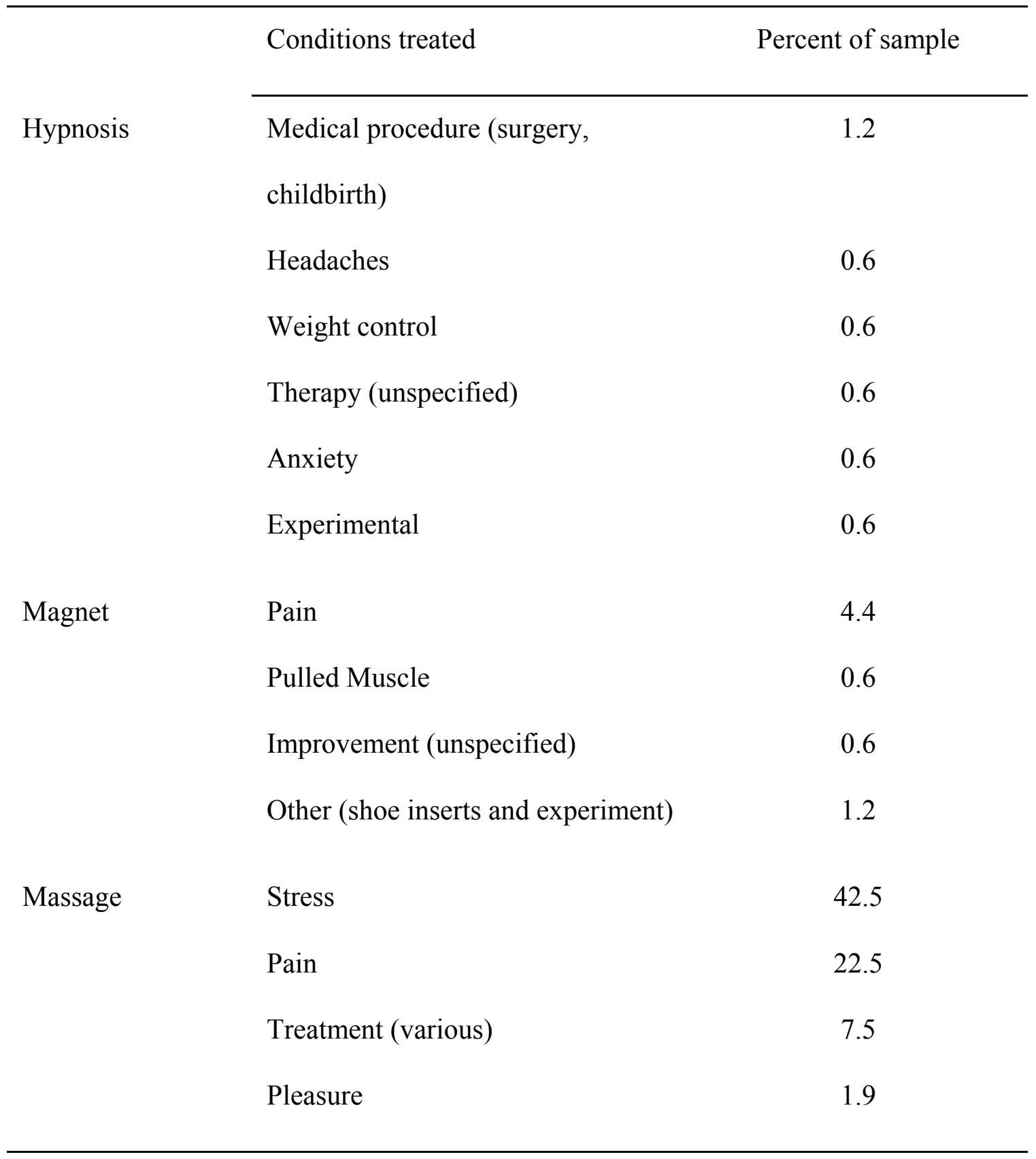

Notes. Sample $\mathrm{N}=160$. Some participants reported multiple conditions for therapies used. 
Table 10

Conditions for Which Meditation, Ornish Diet, Therapeutic Touch, and Yoga Were Used

\begin{tabular}{|c|c|c|}
\hline & Conditions treated & Percent of sample \\
\hline \multirow[t]{5}{*}{ Meditation } & Stress & 25.6 \\
\hline & Spiritual/personal growth & 6.2 \\
\hline & Treatment (various) & 4.4 \\
\hline & Pain & 1.2 \\
\hline & Other & 2.5 \\
\hline \multirow[t]{3}{*}{ Ornish diet } & Weight control & 0.6 \\
\hline & Cholesterol control & 0.6 \\
\hline & Treatment (unspecified) & 0.6 \\
\hline \multirow[t]{5}{*}{ Therapeutic touch } & Treatment (various) & 2.5 \\
\hline & Pain & 1.9 \\
\hline & Pleasure & 0.6 \\
\hline & Relaxation & 0.6 \\
\hline & Sensitivity training & 0.6 \\
\hline \multirow[t]{5}{*}{ Yoga } & Stress & 13.1 \\
\hline & Exercise/flexibility & 13.1 \\
\hline & Mind-body connection & 2.5 \\
\hline & Energy & 1.9 \\
\hline & Treatment (unspecified) & 1.2 \\
\hline
\end{tabular}


Notes. Sample $N=160$. Some participants reported multiple conditions for therapies used. 


\section{Table 11}

$\underline{\text { Regression and Correlation Coefficients for Predictor Variables in Hypotheses One }}$ through Five

\begin{tabular}{|c|c|c|}
\hline & $\begin{array}{l}\text { Correlation } \\
\text { coefficient (r) }\end{array}$ & $\begin{array}{l}\text { Regression } \\
\text { coefficient }(\beta)\end{array}$ \\
\hline Neuroticism & -0.082 & . \\
\hline Extraversion & $0.164 * *$ & \\
\hline Openness & $0.296 * *$ & $.296^{\mathrm{a}}$ \\
\hline Compliance & 0.032 & \\
\hline Humility & 0.026 & \\
\hline Internal Locus of Control & 0.046 & \\
\hline
\end{tabular}


Table 12

$\underline{\text { Regression and Correlation Coefficients for Predictor Variables in Hypothesis Six }}$

\begin{tabular}{lll}
\hline & Correlation & Regression \\
& coefficient $(\mathrm{r})$ & coefficient $(\beta)$ \\
\hline Neuroticism & -0.082 & \\
Extraversion & $0.164^{* *}$ & $.309^{\mathrm{a}}$ \\
Openness & $0.296^{* *}$ & \\
Compliance & 0.032 \\
Humility & 0.026 \\
Internal Locus of Control & 0.046 \\
\hline
\end{tabular}

${ }^{\mathrm{a}}$ Openness accounted for $8.5 \%$ of the variance in the number of therapies tried among those who had experienced a transformational event.

$* * \mathrm{p}<.01$. 
Table 13

Overall Perceived Efficacy and Perceived Effectiveness of Individual Unconventional

Therapies Tried

\begin{tabular}{|c|c|c|c|}
\hline & $\begin{array}{l}\text { Number } \\
\text { reporting }\end{array}$ & $\begin{array}{c}\text { Mean } \\
\text { effectiveness }^{\mathrm{a}}\end{array}$ & $\begin{array}{l}\text { Standard } \\
\text { deviation }\end{array}$ \\
\hline Overall perceived efficacy & 139 & 5.6 & 0.97 \\
\hline Massage & 114 & 6.1 & 0.97 \\
\hline Therapeutic touch & 9 & 5.8 & 1.09 \\
\hline Meditation & 59 & 5.7 & 1.15 \\
\hline Yoga & 51 & 5.5 & 1.22 \\
\hline Chiropractic & 42 & 5.3 & 1.49 \\
\hline Hypnosis & 7 & 5.0 & 1.15 \\
\hline Acupuncture & 4 & 5.0 & 1.41 \\
\hline Ornish diet & 3 & 4.7 & 1.15 \\
\hline Ginkgo biloba & 20 & 4.6 & 1.19 \\
\hline Magnet & 11 & 3.8 & 1.72 \\
\hline
\end{tabular}

$\overline{\text { aSeven-point Likert-type scale (1 = "Extremely detrimental," } 7 \text { = "Extremely effective"). }}$ 
Table 14

Functional Perceptions of Unconventional Therapies Compared to NCCAM (2001)

Major Domains

\begin{tabular}{|c|c|c|}
\hline & NCCAM (2001) major domain(s) & Matched NCCAM ${ }^{\mathrm{a}}$ \\
\hline \multirow[t]{2}{*}{ Meditation } & Alternative medical system \& & 83.4 \\
\hline & Mind-body intervention & \\
\hline Hypnosis & Mind-body intervention & 79.7 \\
\hline \multirow[t]{2}{*}{ Massage } & Alternative medical system \& & 79.4 \\
\hline & Manipulative/body-based system & \\
\hline Magnet & Energy therapy & 71.3 \\
\hline Chiropractic & Manipulative/body-based system & 70.7 \\
\hline Ginkgo biloba & Biological-based therapy & 60.7 \\
\hline Ornish diet & Biological-based therapy & 42.9 \\
\hline \multirow[t]{2}{*}{ Yoga } & Alternative medical system \& & 36.7 \\
\hline & Mind-body intervention & \\
\hline Acupuncture & Alternative medical system & 31.0 \\
\hline Therapeutic touch & Energy therapy & 30.2 \\
\hline
\end{tabular}

${ }^{\mathrm{a}}$ Values are percent of those who had heard of that therapy. 


\section{CIRRICULUM VITAE}

NAME: $\quad$ Kenneth George Lombart

ADDRESS: $\quad$ Department of Psychological and Brain Sciences

University of Louisville

Louisville, KY 40292

E-MAIL ADDRESS: KG.Lombart@1976.usna.com

DOB: $\quad$ Rochester, New York - April 26, 1954

EDUCATION

\& TRAINING:

B.S., Mathematics

United States Naval Academy

1972-76

M.S.E.E., Communications Engineering

Naval Postgraduate School

1982-84

M.A., Industrial/Organizational Psychology

University of New Haven

1991-93

M.A., Clinical Psychology

University of Louisville

1994-98

Ph.D., Clinical Psychology

University of Louisville

1994-2002

PROFESSIONAL

SOCIETIES: $\quad$ American Psychological Association

Kentucky Psychological Association

Society for Psychotherapy Research

The Institute of Electrical and Electronics Engineers 


\section{NATIONAL/INTERNATIOAL MEETING PRESENTATIONS:}

Eells, T.D., Kendjelic, E.M., Lucas, C., Lombart, K., Morris, R. (1998, June). Do expert cognitive-behavioral and psychodynamic psychotherapists think differently than novices? Paper presented at the $29^{\text {th }}$ annual meeting of the Society for Psychotherapy Research, Snowbird, UT.

Eells, T.D., Lombart, K., Turner, L.C., \& Morris, R. (1999, June). Expertise in psychotherapy case formulation and treatment planning. Paper presented at the $30^{\text {th }}$ annual meeting of the Society for Psychotherapy Research, Braga, Portugal.

Eells, T.D., Lombart, K.G., \& Turner, L.C. (2000, June). Expertise in psychotherapy case formulation and treatment planning. Paper presented at the $31^{\text {st }}$ annual meeting of the Society for Psychotherapy Research, Chicago, IL.

Lombart, K.G. \& Salmon, P.G. (2000, April). Preferences for stress reduction modalities as a function of personality traits. Poster session presented at the $21^{\text {st }}$ annual meeting of the Society of Behavioral Medicine, Nashville, TN.

Lombart, K.G., Turner, L.C., \& Eells, T.D. (2000, June). Expertise in psychotherapy case formulation and treatment planning: Comprehensiveness, elaboration, and systematic process. Paper presented at the $31^{\text {st }}$ annual meeting of the Society for Psychotherapy Research, Chicago, Illinois. 